OCRE -53701

D386 014088

\title{
The Vacuum Vessel for the Tandem Mirror Fusion Test Facility
}

\author{
Jerry w. Gerich
}

Manuscript date: March 10, 1986

\section{DSCLAIMIX}

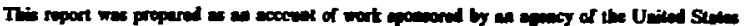

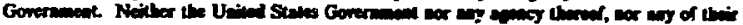

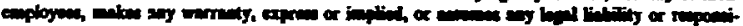

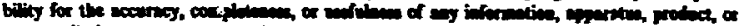

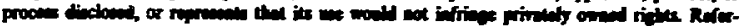

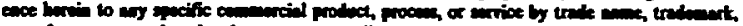

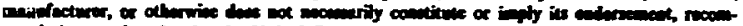

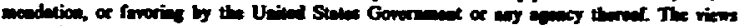

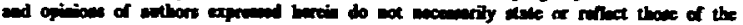

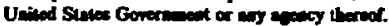

\section{LAWRENCE LIVERMORE NATIONAL LABORATORY University of California - Livermore, California - 94550}

Available from: Nationa: Technical Information Service • U.S. Department of Commerce 5285 Port Royal Road - Springfield, VA 22161 - A02 - (Microfiche 401)

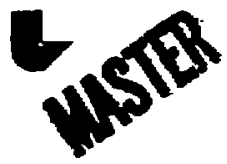




\section{Contents}

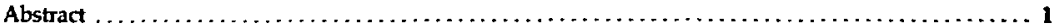

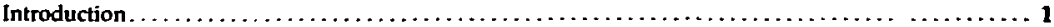

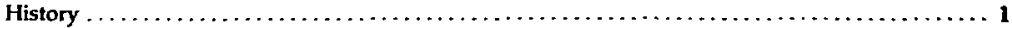

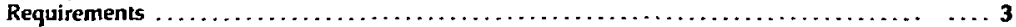

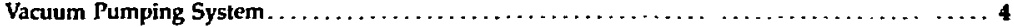

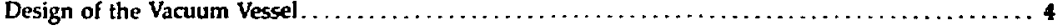

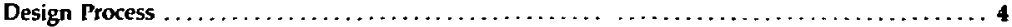

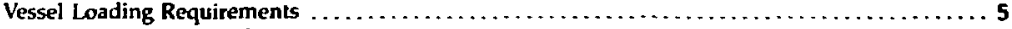

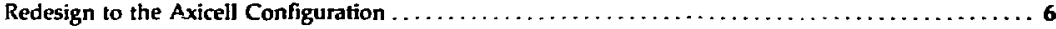

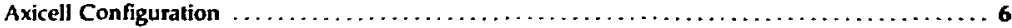

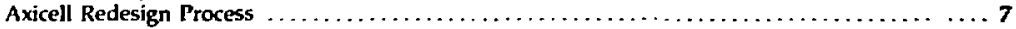

Three-Dimensional Finite-Element Models $\ldots \ldots \ldots \ldots \ldots \ldots \ldots \ldots \ldots \ldots \ldots \ldots \ldots \ldots \ldots, \ldots \ldots$

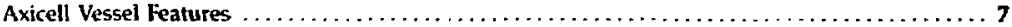

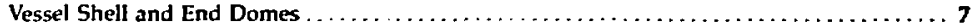

Neutral-Beam Domes $\ldots \ldots \ldots \ldots \ldots \ldots \ldots \ldots \ldots \ldots \ldots \ldots \ldots \ldots \ldots \ldots \ldots \ldots \ldots$

Vessel-Shell Stiffeners $\ldots \ldots \ldots \ldots \ldots \ldots \ldots \ldots \ldots \ldots \ldots \ldots \ldots \ldots \ldots \ldots \ldots \ldots \ldots$

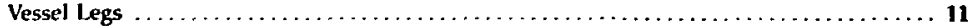

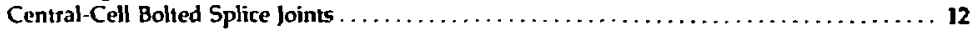

Center-Vessel Support Structure $\ldots \ldots \ldots \ldots \ldots \ldots \ldots \ldots \ldots \ldots \ldots \ldots \ldots \ldots \ldots \ldots \ldots \ldots$

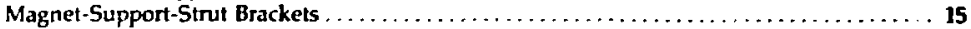

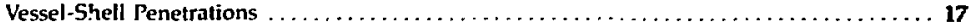

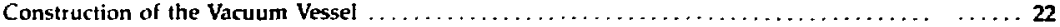

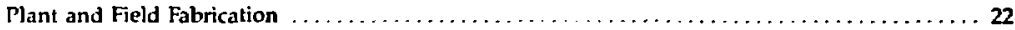

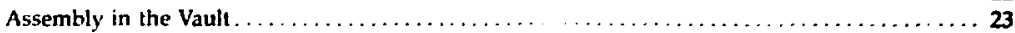

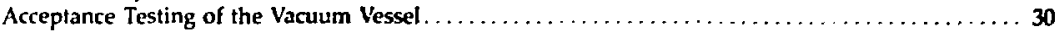

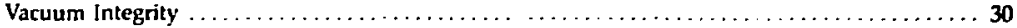

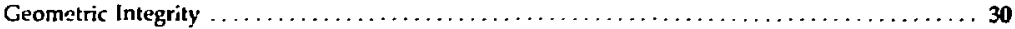

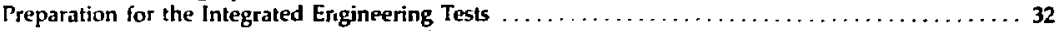

Magnet Installation and Center-Vessel Reassembly $\ldots \ldots \ldots \ldots \ldots \ldots \ldots \ldots \ldots \ldots \ldots \ldots, 32$

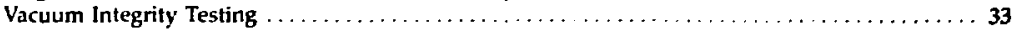

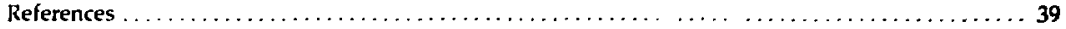




\title{
The Vacuum Vessel for the Tandem Mirror Fusion Test Facility
}

\begin{abstract}
In 1980, the U.S. Department of Energy gave the Lawrence Livermore National Laboratory approval to design and build a tandem Mirror Fusion Test Facility (MFTF-B) to support the goals of the National Mirror Program. We designed the MFTF-B vacuum vessel both to maintain the required ultrahigh vacuum environment and to structurally slipport the 42 superconducting magnets plus auxiliary internal and external equipment. During our design work, we made extensive use of both sinple and complex computer models to arrive at a cost-effective final configuration. As part of this work, we conducted a unique dynamic analysis to study the interaction of the 32,000-tonne concreteshielding vault with the 2,850 -tonne vacuum vessel system. To maintain a vacuum of $2 \times 10^{-8}$ Torr during the physics experiments inside the vessel, we designed a racuum pumping system of enormous capacity. The vacuum vessel (4200- $\mathrm{m}^{3}$ interial volume) has been fabricated and erected, and acceptance tests have been completed at the Livermore site. The rest of the machine has been assembled, and individual systems have been successfully checked. On October 1, 1985, we began a series of integrated engineering tests to verify the operation of all components as a complete system.
\end{abstract}

\section{Introduction}

\section{History}

The first of three versions of the Mirror Fusion Test Facility (MFTF) originated in 1977 when the U.S. Department of Energy (DOE) gave Lawrence Livermore National Laboratory (LLNL) approval to design and build a simple, single-cell mirror machine to explore physics scaling laws and to advance the technology of mirror fusion devices. This machine had a $1600-\mathrm{m}^{3}$ vacuum vessel. Suspended inside the vessel were a pair of superconducting $\mathrm{C}$-shaped magnets, called the yin-yang pair. This vessel also supported the internal cryopumping system, the external rough and high vacuum-pumping system, the neutralbeam injectors, and the diagnostic system. This entire, 1000-tonne, machine rested on a concrete foundation and was surrounded by a 2 -m-thick concrete-shielding vault.

In 1979, we at LLNL built and operated the first tandem mirror machine. As a result of our significant achievements with this Tandem Mirror Experiment (TMX), we received DOE approval in 1980 to change the single-cell MFTF to a tandem mirror design, which was the second version of MFTF. This meant adding a center vessel with solenoid and transition magnets and also duplicating the original vacuum vessel and yin-yang magnets at the other end of the machine. In addition, auxiliary C-shaped magnets, called A-cells, were placed outboard of the two yin-yang magnets. This change in the configuration required an extension to each of the end vessels: this extension supported the new magnets. We named this new A-cell configuration the tandem Mirror Fusion Test Facility, or MFTF-B.

The detailed design work on MFTF-B began just as our engineering staff and their subcontractors were finishing the assembly of the original MFTF. During the first half of fiscal year 1982 , we conducted a very successful series of engineering tests on the MFTF vacuum vessel, yin-yang 
magnets, and other systems to verify their design parameters. Immediately after these extensive tests, we disassembled MFTF for reconfiguration to the tandem MFTF-B A-cell design. The new machine incorporated essentially all of the existing hardware, including the vacuum :essel and its foundation.

In 1982, we made one other major change to the vacuum vessel, the magnets, and most of the other systems. This physics-initiated modification was undertaken to complement the main-line approach to mirror-fusion reactors. This thi-d configuration of MFTF was called the MFTF-B Axicell design. It increased the number of major magnets from 22 to 26 and eventually added 16 smaller magnets called trim coils. These changes had a large impact on the vacuum-vessel design-every magnet was relocated, cassing changes in the loading pattern. Also, the end-vessel extensions were eliminated because the resident $A$-cell magnets were not needed. All of these design changes required new structural calculations, but, fortunately, fabrication of the tandem vacuum vessel had not begun because we had been anticipating these changes for many months. Figure 1 shows the overall configuration of the MFTF-B Axicell, its major systems, and its location inside the building and concrete shielding vault.

The detailed design, fabrication, and field erection of both the MFTF and the MFTF-B vacuum vessels were awarded to subcontractors througl, competitive bidding processes. The CVI Corporation of Columbus, Ohio won the contract for MFTF, which included the vacuum vessel; the internal, extemal, and rough vacuum-pumping systems; and the cryogenic system. The CVI Corporation subcontracted this initial vacuum vessel to the Pittsburgh-Des Moines Corporation (PDM) of Pittsburgh, Pennsyluania. Several years later, after another competitive bidding process, PDM won the contract for the MFTF-B vacuum vessel on July 1, 1981. Very close cooperation among the CVI, PDM, and LL.NL. engineering staffs ensured that all the system requirements sere met for these challenging projects.

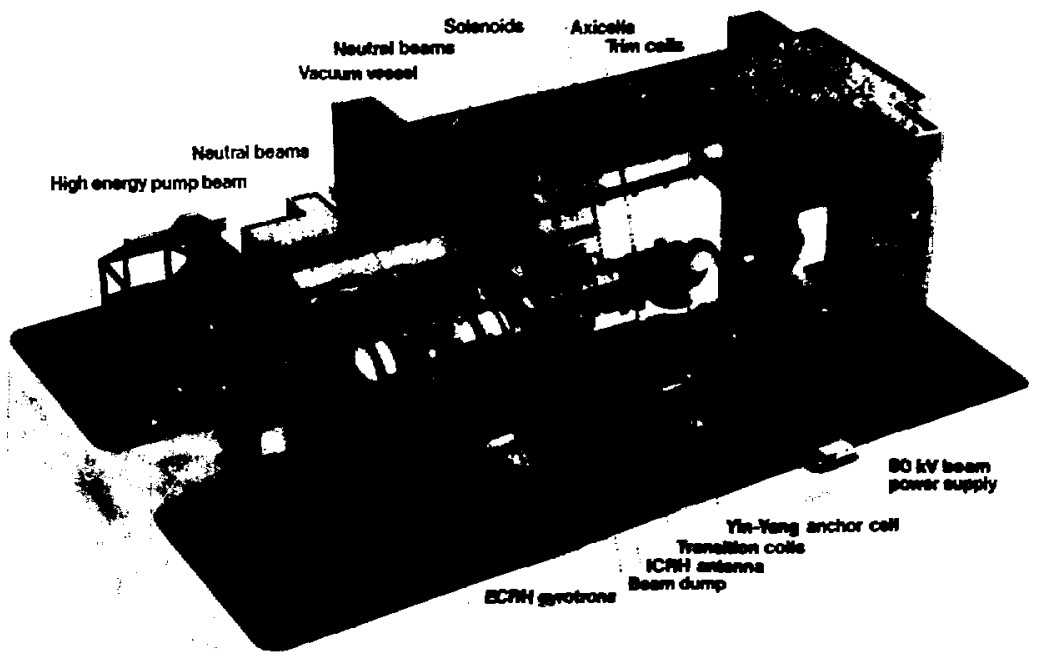

Figure 1. An artist's drawing of the MFTF-B axicell facility showing the building and bridge crane, concreteshielding vault, vacuum vessel and its supports, superconducting magnets, and some of the auxiliary systems. 


\section{Requirements}

The primary functions' of the ivifrf-B vacuum vessel are

1. Maintain the vacuum environment created by the pumping system for the plasma experiments.

2. Provide the structural support for the superconducting magnets and the other internal and external systems.

In addition, the design of the central cell requires a modular construction that allows for reconfiguration of the inboard magnet set without first removing the giant yin-yang magnets.

We chose ASTM A240 Type-304 stainless steel for the varuum vessel because it is nonmagnetic, has good fracture toughness and welding properties, is readily available in many standard shapes, and is reasonably priced. Most other parts of the vessel system, such as the support legs and magnet attachment brackets, are also made of the Type-304 stainless steel.

To maintain the required high vacuum, we polished the entire inner surface of the vessel. We also placed most of the stiffening structure on the outside of the vessel, which had the advantage of reducing the interior vessel surface area for ease of cleaning and for lower outgassing during vacuum operations.

The basic size and shape of the vacuum vessel are determined by the geometry of the superconducting magnet set. We allowed some additional space for cryopanels, neutral-beas dumps, plasma end dumps, and worker access, and arrived at a horizontal, central-cell cylinder that is $8 \mathrm{~m}$ in diameter and $20 \mathrm{~m}$ in length, capped at each end by horizontal, cylindrical end vessels, $10.6 \mathrm{~m}$ in diameter and $16 \mathrm{~m}$ in length. With the conical sections that join the end vessels to the center vessel plus the spherical end domes, the entire assembly measures $58 \mathrm{~m}$ in length and encompasses a high-vacuum volume of $4200 \mathrm{~m}^{3}$ (Fig. 2).

In the central-cell region, we met the reconfiguration constraints by designing six removable vessel modules, each containing Iwo of the solenoid magnets. Originally, these six modules encompassed the entire $20-\mathrm{m}$ length of the center ressel. However, when the machine was reconfigured to the axicell design, we moved the solenoid magnets closer together. Consequently, the center vessel now consists of the six removable modules

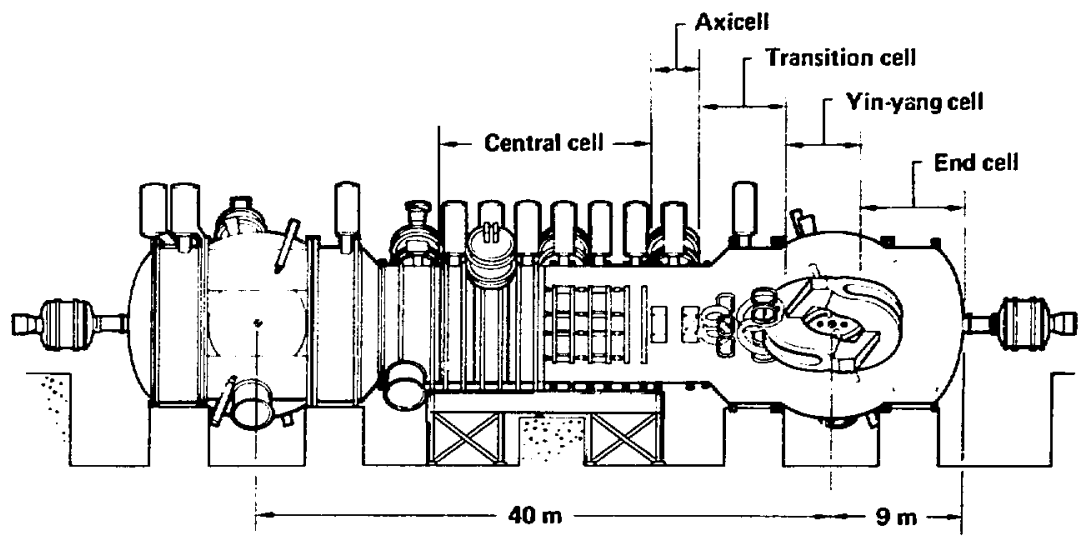

Figure 2. An elevation view of MFTF-B with the east end of the vessel cut away. The different regions of the machine are shown along with the shape of the vacuum-vessel skin. Each end vessel is supported on massive concrete piers, and th z central cell is rigidly held by a steel structure with longitudinal cross bracing Centered on each of the two yin-yang cells are four spherically shaped neutral-beam domes. 
plus a 4-m-long, 8-m-diameter transition cylinder at each end. These cylinders are welded to the conical sections of the end vessels.

\section{Vacuum Pumping System}

The MFTF-B machine requires a vacuum pumping system that can take the vacuum vessel and its contents from atmospheric pressure to a base pressure of $1 \times 10^{-8}$ Torr in less than two days. In addition, after deuterium is injected during physics operations, this equipment must produce a pressure of $2 \times 10^{-8}$ Torr before each physics experiment. There are three main components of the pumping system that perform these tasks. ${ }^{2}$ First, the four roughing trains, each consisting of a mechanical pump and two Roots blowers, evacuate the vessel to $1 \times 10^{-2}$ Torr. Second, ten high-vacuinu cryopumps that are mounted on the outside of the vacuum vessel bring it to $1 \times 10^{-6}$ Torr. (These pumps can be isolated from the internal vacuum environment and regenerated.) Third,
$1000 \mathrm{~m}^{2}$ of internally mounted liquid-nitrogenshielded liquid-helium cryopanels are brought on line by introducing the cryogens, thus obtaining the $1 \times 10^{-1}$ Torr base pressure.

During physics experiments, plasma shots can occur at five-minute intervals, and the deuterium that is injected is actively pumped internally by the cryopanels. ${ }^{3}$ The most difficult residual gases that we pump are the light ones-helium, hydrogen, and hydrogen-deuteride-all of which are introduced during the 30-s duration of the plasma shots. This pumping is performed by feur of the ten high-vacuum pumps that operate at $2.8 \mathrm{~K}$, which is below the normal operating tem. perature of $4.5 \mathrm{~K}$. These are two-stage pumps that cryocondense the hydrogen and hydrogendeuteride and incorporate an argon-injection, cryosorption system for pumping the helium. (We also installed four $46-\mathrm{cm}$-diameter turbomolecular pumps on the vessel. Their primary use is during the leak checking of the vessel, but they can also be used to augment the regular vacuum-pumping system.)

\section{Design of the Vacuum Vessel}

\section{Design Process}

Soon after the tandem mirror concept was approved in 1980, LLNL began development of an extensive, three-dimensional, finite element model of the new vacuum vessel. The results from this preliminary model provided the basis for the procurement specification for the vessel, and they also generated interface geometry and rough loading values for other project components, such as the vessel foundation. This stage was completed in early 1981 .

Our preliminary design work with the finite element model and an improved version of the SAP4 computer codet solidified the general vessel configuration as a thin-walled cylinder for vacuum isolation with substantial external stiffening to handle the additional structural demands. (This is the same design concept as the original MFTF vessel.) At each magnet location, we placed a circumferential or ring stiffener with a " $\mathrm{T}$ " cross section. Although the ring stiffener itself had a " $T$ " cross section, when welded to the vacuum vessel skin, the effect was the same as an I-beam cross section. These ring stiffeners rested on a set of legs that were fastened to concrete piers under the end vessels and to a steel structure under the center vessel. To carry vessel loads in the longitudinal direction, we reinforced the shell with various additional stiffeners along the length of the shell surface.

After PDM joined the vacuum vessel team, our design effort branched into several parallel efforts, pursuing different objectives. Our LLNL team refined and updated the vessel model to reflect the evolving physics and engineering developments so that we could generate design criteria for both the concrete foundations and the magnetsupport struts. In this way, we could also verify the PDM design calculations.

The PDM engineering group split into several design teams to provide a detailed design and stress analysis for the entire vessel. One PDM team developed two-dimensional models (in the transverse plane) of the approximately two-dozen ring stiffeners and sized them with the ANSYS computer code. A second team generated a twodimensional ANSYS beam model of the vessel 
and its supporting legs (in the vertical longitudinal plane) to study the distribution of loads in the axjal direction. Other PDM engineering staff employed hand and computer calculations to determine the thickness of the shell plate to be used in fabricating the thin-wall vacuum cylinder. These calculation methods were also used to analyze local features such as the end domes and support legs.

To meld these design efforts and to account for three-dimensional interactive effects, the PDM analytical group began a finite element model synthesizing the entire vacuum vessel, the magnets, the supporting legs, and the foundations. To permit stress analysis, this detailed model grew to twice the size of the LLNL model and consisted of over 4600 elements. The initial size and shape of the features in this threedimensional model came directly from the results of the two-dimensional models and hand calculations.

Throughout the development of the PDM model and the refinement of the LLNL model, careful coordination and cooperation between the teams was necessary to allow meaningful comparisons of the results. In one cooperative effort, LLNL developed very detailed three-dimensional models of the end-vessel-leg and neutral-beamdome regions. The understanding gained from these small models allowed PDM to generate much simpler (less elements) models of these regions for inclusion in their large model. Because each of these regions is repeated four times in the large model, there was a significant decrease in computer run time with the SAP4 code.

During our early design effort at LLNL, we had reason to believe that we could substantially reduce the magnitude of the transverse and longitudinal components of earthquake acceleration because of the interactions of the vacuum vessel and its foundation with the soil and with the surrounding massive concrete vault. To study this soil-structure-interaction (SSI) effect and tc verify the estimate of a $25 \%$ load reduction, which we decided to use as our design basis, LLNL contracted with Structural Mechanics Associates (SMA). They used an existing finite-element model of the vault, the LLNL vessel model, and local soil data to perform a CLASSI computercode analysis.

To do the response spectrum analysis with the SAP4 code and the LLNL and PDM models, we needed to know or estimate a damping coefficient for this dynamic portion of the calculations. Because we had already built the MFTF vessel and installed the large yin-yang magnet pair inside, we were able to perform a series of dynamic excitation tests and measure the actual decay rate, or structural damping, at many different locations on the vessel.5 thie found the average damping coefficient was 5\%, considerably higher than the 1 to $2 \%$ that is regularly used for nuclear power plant design. Thus, the use of this higher damping value produced significantly lower earthquake design loads for the MFTF-B vacuum vessel.

The design proces: for the MFTF-B vacuum vessel was highly iterative, and the process involved not only the use of the codes and methods just mentioned above, but it also took advantage of considerable information and results generated by other groups. For an excellent overview of the analysis methodology that our project used, see Karpenko and $\mathrm{Ng}$ in Ref. 6.

\section{Vessel Loading Requirements}

To properly perform the magnetic fusion experiments, the vacuum vessel must sustain numerous loading situations, both static and dynamic. The seven static forces ${ }^{7}$ producing these loads on the vessel are defined as follows:

1. Gravity Load. The gravity load is caused by the $1-\mathrm{g}$ force acting straight downward on the entire mass of the vessel and the components it supports. These masses are the ressel itself $(1100$ tonnes), the superconducting magnet set (1250 tonnes), and the auxiliary components inside and outside the vessel ( 500 tonnes).

2. External Pressure Load. The external pressure load is caused by the standard atmospheric pressure acting on the vessel shell when the vessel is under vacuum, plus an additional $10 \%$ of the atmospheric load to account for magnetic pressure on the shell resulting from the sudden collapse of the magnetic field.

3. Thermal Cooldown Load. The thermal cooldown load is caused by the magnets cooling to $4 \mathrm{~K}$, while the vessel remains at room temperature. Because the magnets are connected to the vessel by a number of support struts on each magnet group, the possibility exists for an overconstrained strut system to generate thermalcontraction loads. This happened with the yin-yang system in the original MFTE. However, in MFTF-B, we were able to decrease the seven yin-yang support struts to six, thereby removing all thermal cooldown loads. We always included this load case in our computer analysis, though, to ensure that design changes did not catch us with an over-constrained system. 
4. Envirenmental Therinal Load. The environmentai thermal load is caused by the variation in the air temperature surrounding the vessel. Because MFTF-B will be enclosed in the 32,000-tonine concrete vault during nomal physics operations, we used a thermal excursion of only $5.6^{\circ} \mathrm{C}$ for our calculations.

5. Magnetic Normal Load. The magnetic normal load is caused by large axial forces that are generated by the magnet set during normal operation. These forces are transmitted into the vessel by a series of drag struts.

6. Magnetic Fault Load. The magnetic fault load is caused by additional and, in many cases, much larger axial forces that are generated when one or several magnets switch from superconducting to norma!. Nunerous fautt conditions are possible. We generated a icad matrix and then chose the most severe case to use as our design busis for each magnet group.

7. Magnet Misalignment Load. The magnet misaligrment load is caused by a radial or side force that develops on energized magnets that are not perfectly aligned. The magnitude of these loads is determined by the tolerances that can be obtained during the installation of the entire magnet set. Also, for the MFTF-B axicell magnet set, the trim coils produce additional side loads when they are energized.

These static forces make up the seven static load cases in our SAP4 stress analysis. Our procedure is to first calculate every load case separately, so we can study each situation to ensure that the model is behaving properly. Next, we sum the loads algebraically for each region to obtain the total static component of the load. Then, for several combinations of these static loads, we compare the stresses generated by these loads with the allowable stress for the Type-304 stainlesssteel vessel material.

Dynamir forces acting on the vacuum vessel are based exclusively on the most severe credible earthquake postulated for Livermore, California, where MFTF-B is located. (Livermore is a region with active earthquake faults.) This site-specific spectrum has a zero-period acceleration (ZPA) of $0.25 \mathrm{~g}$ and is applied in the two horizontal directions. The vertical excitation is scaled by twothirds of the horizontal ZPA.

During 1982, SMA completed their SSI study on the first configuration of MFTF- $B^{3}$ (the second MFTF design with the A-cell magnets at each end). They found that three separate effects combined to mitigate the earthquake loading on the vessel. First, vibrational energy is radiated into the soil undemeath the vessel foundation and, thus, is lost to the vibrating vessel system. Second, vibrational energy is lost to the soil adjacent to the foundation because of the material damping properties of the soil. Third, the vibrational frequency of the vessel system is lowered because it is driven by the surrounding, more massive, concrete vault. This latter effect shifts the system frequency further away from the peak of the response spectrum and, therefore, lowers the input acceleration levels.

On the average, the SMA analysis showed that the total effect of this soil-structure interaction was to reduce the two horizontal components of the dynamic loads in the vessel to slightly less than $75 \%$ of the values calculated with the SAP4 code. Both LLNL and PDM took advantage of this discovery by lowering response spectrum acceleration input by $25 \%$ in the transverse and longitudinal directions.

The criteria for the MFTF-B vacuum vessel stress ailowables are based on the ASME Pressure Vessel Code Section Vliil, Divisions 1 and 2 (Ref. 2). Stresses are classified as either primary for the pressurized vassel and its stiffeners, or secondary for the nonpressurized legs and supperts. Stress aliowable values are taken from Division 1 , and stress intensity factors for the various load combinations are taken from Division 2. Stress allowables for the legs and component supports are based on AISC allowables. A lower safety r.rargin is applied to the earthquake case because of its low probability of occurrence during the machine's ter:-year design life.

\section{Redesign to the Axicell Configuration}

\section{Axicell Configuration}

As the PDM engineering groups were finishing their design calculations in mid-1982, LLNL decided (with DOE approval) to modify MFTF-B to complement the main-line approach to mirrorfusion reactors. This third MFTF configuration was called the MFTF-B Axicell, and it had a major 
impact on the vacuum vessel system. The main driver of the vessel changes was the magnet system: several magnets were eliminated, many were added, and all were relocated. We deleted the 4-m-long extensions at each end of the vessel, where the two large A-cell magnets had previously resided, and we had to add a new set of vessel legs and a ring stiffener at each end of the central celi to support the four new axicell magnets. Also, because the central-cell solenoid magnets moved from a $2 \cdot \mathrm{m}$ spacing to a $1.25-\mathrm{m}$ spacing, we had to relocate all of the central-cell ring stiffeners and legs.

The existence of more magnets along a shorter machine length tremendously increased the magnetic operating and fault loads. This drove the magnet weights higher because of the need for stronger structural cases; consequently, the vessel gravity and earthquake loads grew proportionately. Additionally, we found that the existing MFTF east-vessel legs and concrete foundations could no longer safely react the higher axicell longitudinal forces. This required us to shift more of the longitudinal load into the central cell where the structural supports and foundations were yet to be built. We accomplished this shift of load by reducing the stiffness of the legs of each end vessel and by increasing the stiffness of the centervessel legs.

\section{Axicell Redesign Process}

With our design teams in place at both LLNL and PDM, our finite element models developed, and our calculational methods proven, the axicell redesign effort progressed rapidly. We were able to quickly resize the main vessel components (e.g., ring stiffeners, legs, and shell plates) with hand calculations and two-dimensional code runs so that we could use this new geometry for updating the three-dimensional, complete vessel models. In addition, the teams immediately concentrated design and nodeling effort in regions of the machine that our experience indicated would be overstressed from the new, higher loads.

\section{Three-Dimensional Finite-Element Models}

The two, three-dimensional finite-element models of the vessel were central to the design effort at both PDM and LLNL. This was true even though the two models had quite different pur- poses. The LLNL team developed the first model to aid specification writing, to provide advanced estimates of loading on foundations and magnetsupport struts, and to serve as a course check on the more-detailed model of PDM. The PDM model was designed to capture three-dimensional effects. The model had twice as many elements so that final sizing of vessel parts could be carried out or checked from the load results. This approach using both models worked extremely well for our design teams, and it was particularly valuable when we needed to quickly redesign the vessel to the axicell configuration. For a comprehensive account of the LLNL model, from modeling assumptions to the analysis of the results, see Refs. 7 and 9. Figure 3 is a computer-drawn picture of the LLNL finite-element model.

\section{Axicell Vessel Features}

\section{Vessel Shell and End Domes}

The vessel shell is designed to maintain the vacuum environment. Consequently, it is a thinwalled cylinder almost entirely of a weldedconstruction design consisting of shell-plate thicknesses ranging from 13 to $64 \mathrm{~mm}$. Each outboard unit of the vacuum vessel is a continuously welded structure from the end-dome interface through the transition cylinder in the axicell region (Fig. 4). The six central-cell modules, although of welded construction themselves, are bolted to each other and to the east and west transition cylinders; they are also attached to their underlying, center-vessel support structure with bolts. (This design allows the modules-and their internal magnets - to be removed by the building crane for major maintenance or a change in machine configuration.) The vacuum seal is made by welding a thin, easily removed, steel band between adjacent module flanges and around the vessel circumference.

Sizable increases in the longitudinal loads for this axicell configuration led us to add longitudinal stiffening bars to the central-cell-module shells. These bars are spaced approximately 10 deg apart around the circumference to provide local shell sections with adequate stiffness against shell buckling. The 45-deg transition cones need a tension ring at the large end and a compression ring at the small end to withstand these higher loads.

The openings to the end vessels are the full vessel diameter to allow for the insertion of the giant yin-yang magnets. The two end domes that 


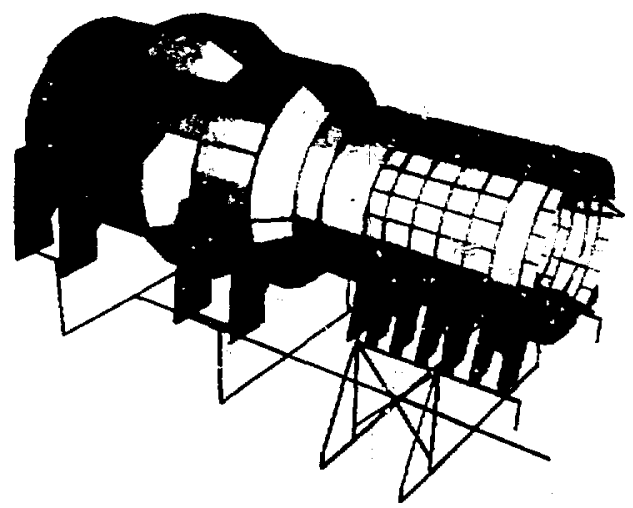

Figure 3. A computer-drann picture of the LLiNL three-dimensional finite-element model of the vacuum vessel, magnets, and support siructure. Because of symmetry about the middle of the mashine, only the western half of tha vessel structure was modeled. The dark lines on the vessel shell are the lccations of longitudinal and circumferential stiffeners. Two of the four neutral-beam domes show prominently on the end vessel.

cover these openings have a $13-\mathrm{mm}$-thick, 9-mradius shell that is stiffened with external ibs (Fig. 5). The vacuum compression load is reacted on the end vessel by compression blocks located around the perimeter of the vessel and in line with the shell plate. These blocks are inside the vacuum seal. PDM used their patented vacuum O-ring seal, called a Flex-Seal, on these end domes, which were built for the sriginal MFTF machine. The key feature of this design is that after it is initially installed and adjusted to fit the mating end-vessel surface, the Flex-Seal does not need to be readjusted if the end dome is removed and replaced.

\section{Neutral-Beam Domes}

The neutral-beam domes are special sections of the vessel shell located in the middle portion of the east and west end vessels. Each end vessel has four neutral-beam domes, which are positioned on the tcp, bottom, and each side of the end vessel (Figs. 1-3). These domes are spherical surfaces with their center of curvature located on the longitudinal centerline of the vessel at the middlf of each cnd vessel. Originally, these dome regions were meant for mounting a large number of heavy neutral-beam injectors and beam dumps in many different configurations. However, as the physies of the facility evolved and the number of injectors mounted on these domes decreased, we dedicated the side domes to diagnotic instruments.

The portion of the shell surface where the injector ports are located is $64 \mathrm{~mm}$ thick. This allows us to machine the rectangular mounting bosses directly into the plate. A gridwork of plate stiffeners on edge is welded to the inside surface of each dome to provide for good load distribution. Each of these 15-tonne neutral-beam dumes was fabricated in the plant, shipped to the LLNL site, and installed as a complete unit (Fig. 6).

\section{Vessel-Shell Stiffeners}

Tre entire vessel shell has an integral, externalstiffening framework to carry the primary loads 


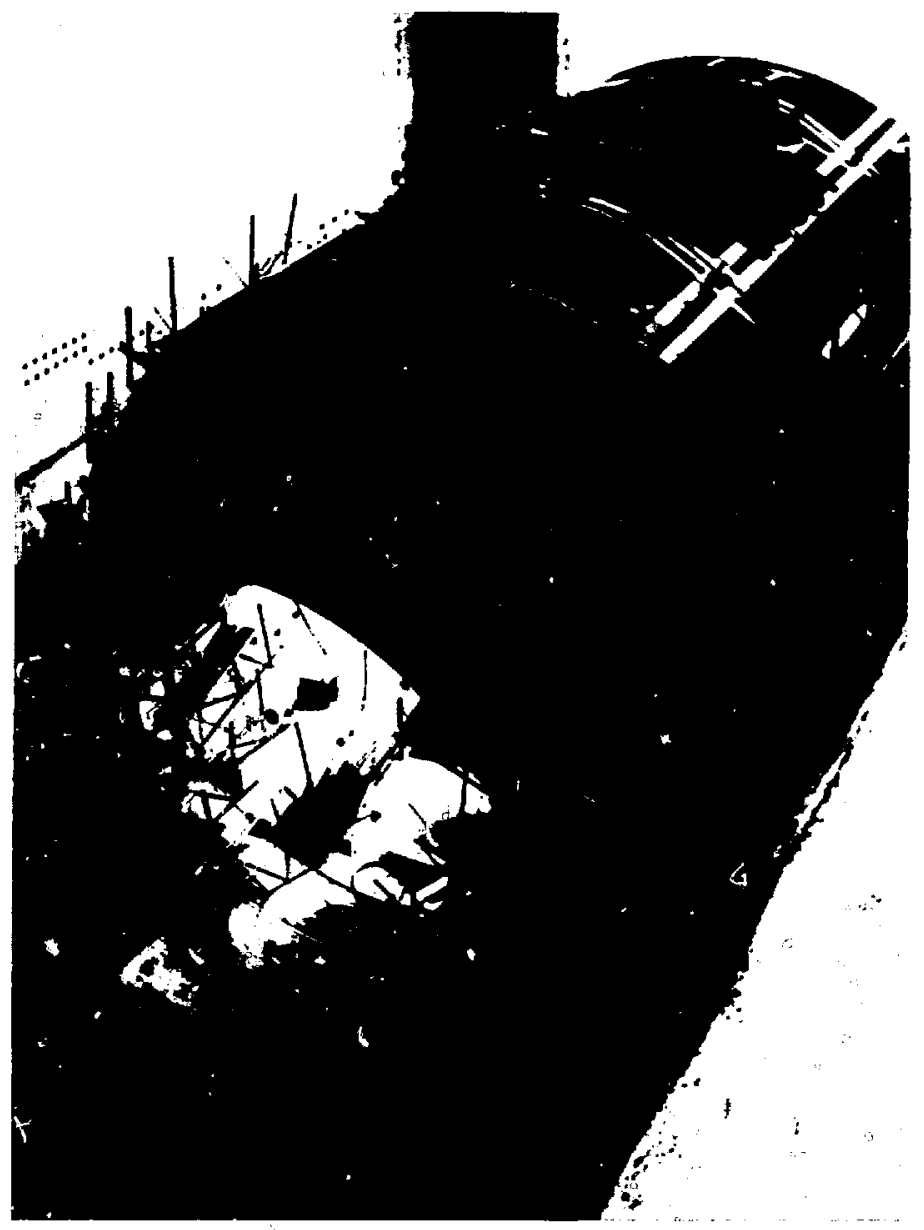

Figure 4. The outboard pottion of the vessel during construction. This entire unit is joined by welding, including the transition cylinder in the foreground, the transition cone, and the end vessel in the background. The central cells will be installed on the inboard rim of the transition cylinder. 


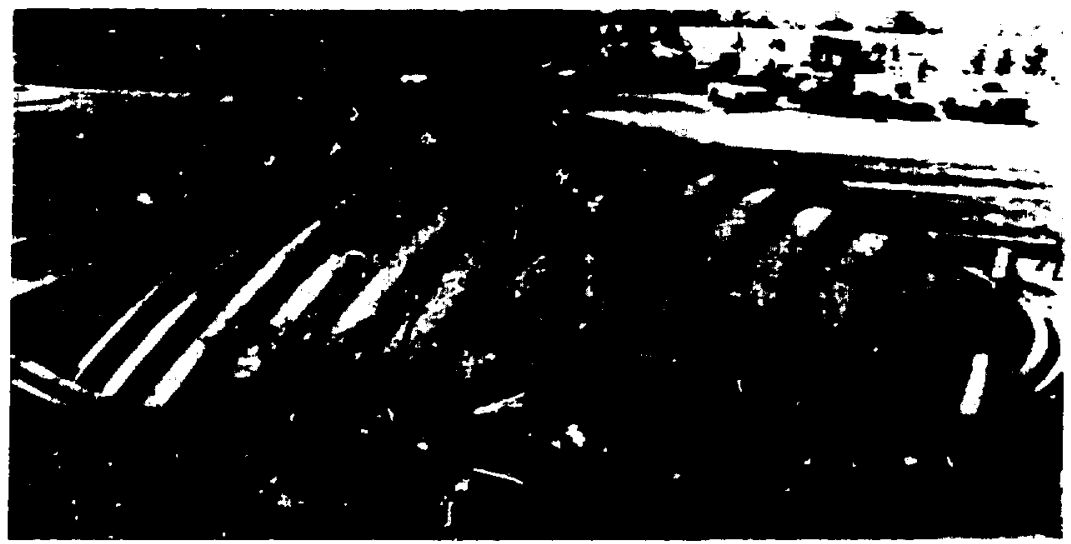

Figure 5. One of two spherically shaped end dones. The verticai ribs and a smaller number of horizonlal ribs on each side provide the external stiffening of the thell plate. The pattern of ports in these ead vescels tends to follow the 45-deg orientation of the yin-yang mapnets.

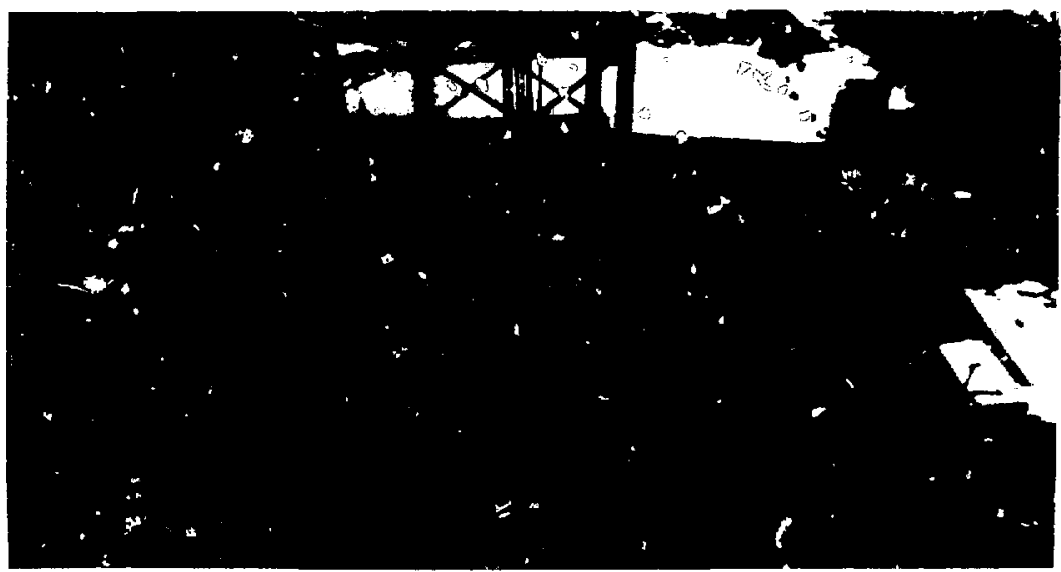

Figure 6. Preparing to lift one of the vacuum vessel's eight neutral-beam domes for installation on the west end vessel. The largest opening is a reclangular access door/port that was designed to allow replacement of the neutral-beam thermal dumps. Eight rectangular neulral-beam injector ports are located on the right side of the dome. During installation, they are covered with plywsod to prolect their machined mounting bosses. 
and address the effects of vessel stability. The two types of stiffeners are circumferential and longitudinal (Fig. 7). Twenty-two of the 26 major magnets are suspended from a circumferential stiffener that has a single " $T$ " cross scrtion, whereas each of the four 91-tonne yin-yang halves require a double " $\mathrm{T}$ " ring. In addition, there is a single ring stiffener (and a set of legs) at each end of the machine to support the weight of the end dome.

There are four sets of Jongitudinal stiffeners of various cross sections, spaced 90 deg apart, and running the length of the 8 -m-diameter center vessel. These stiffeners coincide with the aximuthal location of the drag struts of the three inboard magnet groups. These stif́feners transmit the longitudinal forces of the magnets along the vessel and into the vessei-shell plate; they also trarsmil the racial forces into nearby ring stiffeners. As discussed later. the drag-strut atlachment brackets are actually an integral part of these !ongitudinal stiffeners. The end ressels are also highly stiffened in the longitudinal direction as shown in Fig. 7.

\section{Vessel Legs}

The vacuum vessel is supported by a series of 47 vesse! legs, in pairs. These legs are located on the north and south sides of each ring stiffener. They are made from stainless-steel plate stiffened by ribs and flanges (Fig. 8). Each end vessel is supported by eight legs that are rigidly joined to the four concrete piers (Fig. 9). The four legs that are located at the double ring stiffeners have double wets to carry the weight of the yin-yang magnet set. The 12 sets of legs supporting the

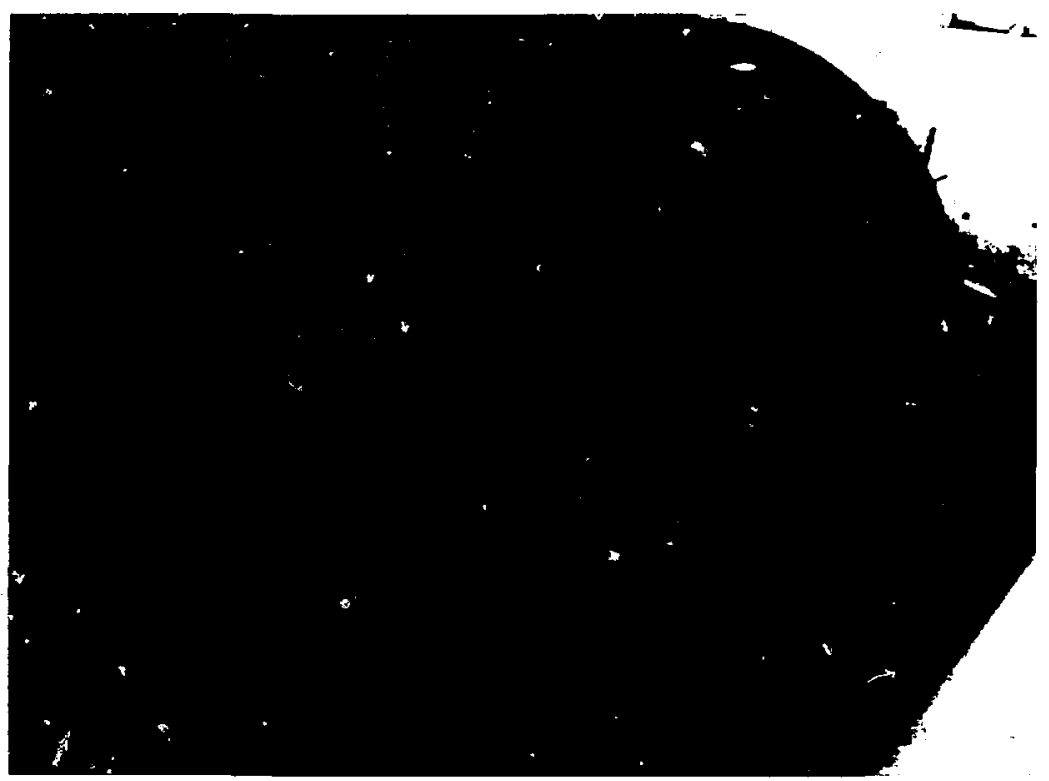

Figure 7. The west end vessel under cosstruction, showing the circumferential and longitudinal stiffener pattern. Notice that the two inboard ring utiffeners (located on each side of the neutral-beam domes) are doubled to carry the immense weight of the yin-yang magnets. 


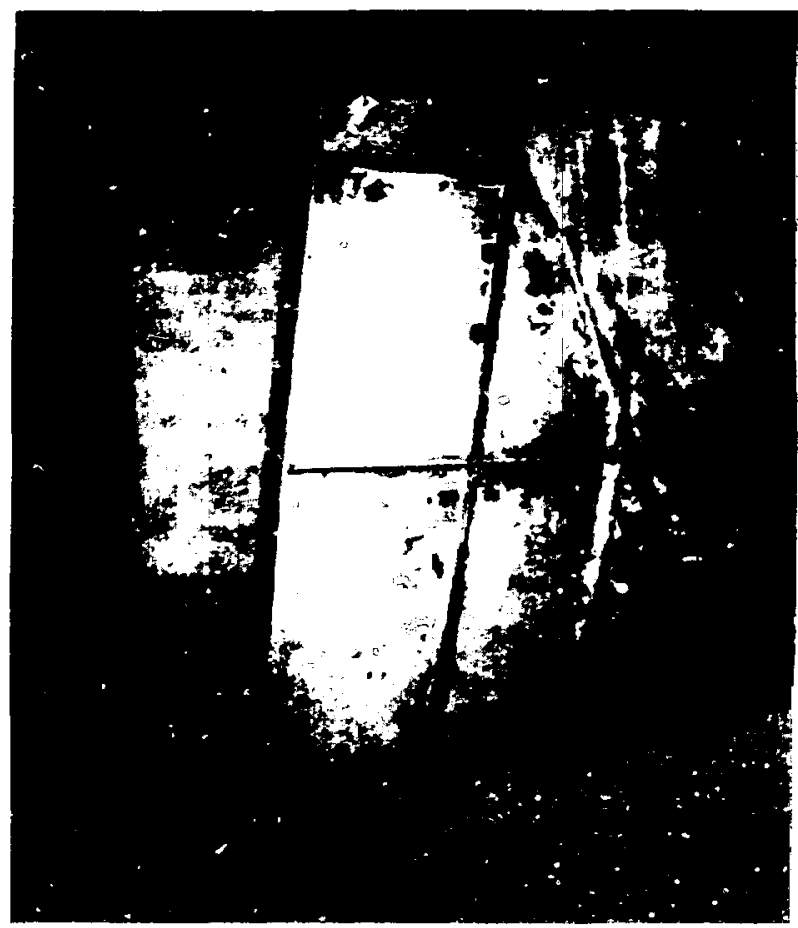

Figure 8. One of the end-venel aingle leg, which will be lifted thto place on the concrete pier that is located behind the les strecture. Thls wainlew-eteet les is stifened with ribs and also has a flange on both the left and right edy. The wpper-right slanied portion of the leg is actually a curved aurface that will be weided directly to vessel ting stiffener.

6 central-cell modules are structurally joined in each module to form a rigid frame (Fig. 10). These 12 irames comprise the main seismic restraint of the vessel in the longitudinal direction. (Recall that this design concept was necessitaied by the higher axicell longitudinal forces combined with the existing, lower-capacity, east-vessel legs.)

\section{Central-Cell Bolted Splice Joints}

The seven splice joints that secure the six central-cell modules to each other and to the east and west transition cylinders must carry tension, compression, and shear loads in additicn to providing a vacuum seal. We set the general layout of these joints early in the design process, but the final details of each individual joint depended on the results of PDM's three-dimensional computer analysis. Actually, we did not appreciate the importance of the circumferential shear loads until after these computer runs were studied. At that time, PDM found that many locally applied loads were transmitted along the shell as shear loads because of the rigidity of the large, stiffened shell. ${ }^{2}$ This resulted in significant, and different, 


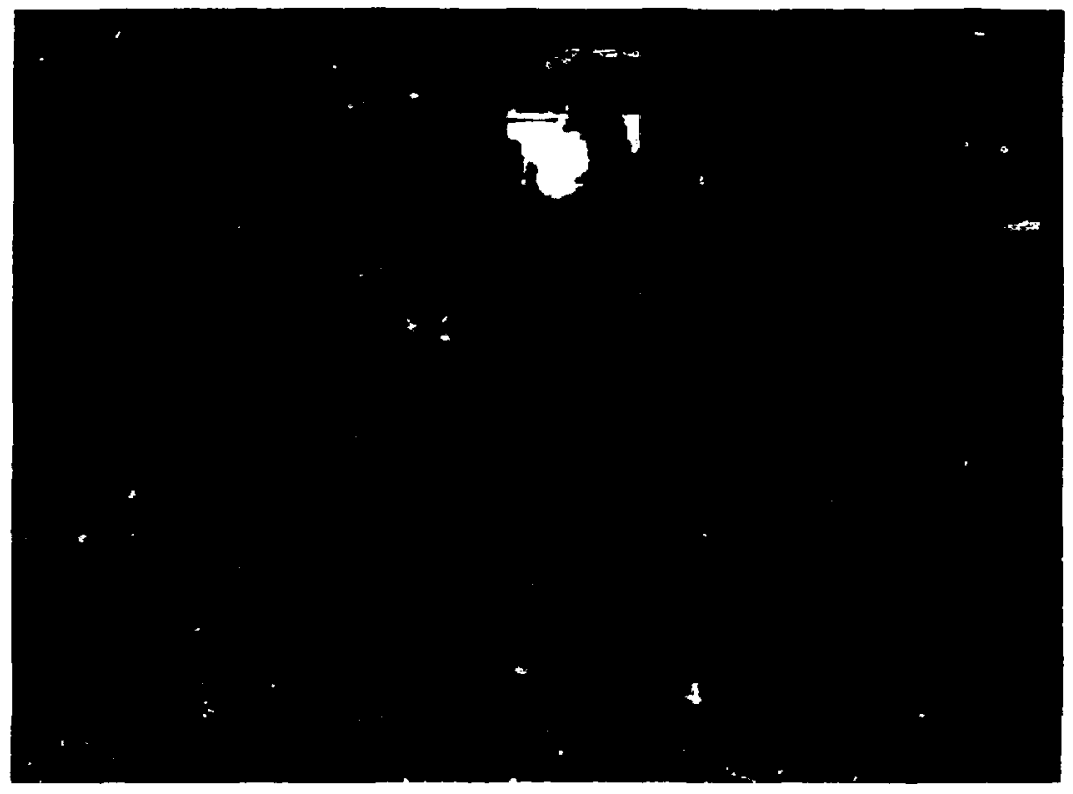

Figure 9. The eight, west-end-vessel legs after being welded to their base plates on the concrete piers. These base plates are joined to the piers by large bolts that are part of a frame deeply embedded in the reinforced concrete. The bolts and nuts provide vertical adjusiment for the end-vessel-can sections that will be placed on these legs. When final alignment is achieved, a concrete grout mixture will be pumped belween the leg base plates and the piers. Running Ieft-to-right across the vault behind the west vessel piers is the U-shaped buttess or shear wall that stabilizes the side walls of the concrete vault. In the center background of this photo is the existing east vacuum vessel that is undergoing modification.

loads at each of the bolted splice joints, three of which required 128 bolts, and four of which required 92 bolts.

The geometrical layout of these joints incorporates a pair of flanges, welded to the adjacent shell plate, that are joined with high strength. nonmagnetic bolts (SA-193 Grade B8). These bolts are located just inside the vessel shell, and they react the tensile and shear loads. The compression loads are reacted through a set of varying-thickness shim blocks located at each bolt and extended radially outward enough to be directly in line with the shell plates. Besides transmitting the compres- sion loads across the joint, these shim blocks serve two other purposes. First, because these shim bolts are custom-machined after adjacent modules are set in their final place, they allow precise positioning of the central-cell modules for magnet-solenoid alignment. Second, because they are easily removed along with the bolts, they provide a 5-to-10-cm-wide gap to facilitate assembly and disassembly of the modules (Fig. 11). After final assembly is completed, the vacuum seal is made by lap-welding a 0.5 -cm-thick stainlesssteel strip (which can be easily removed) around the outer circumference of the flauges. 


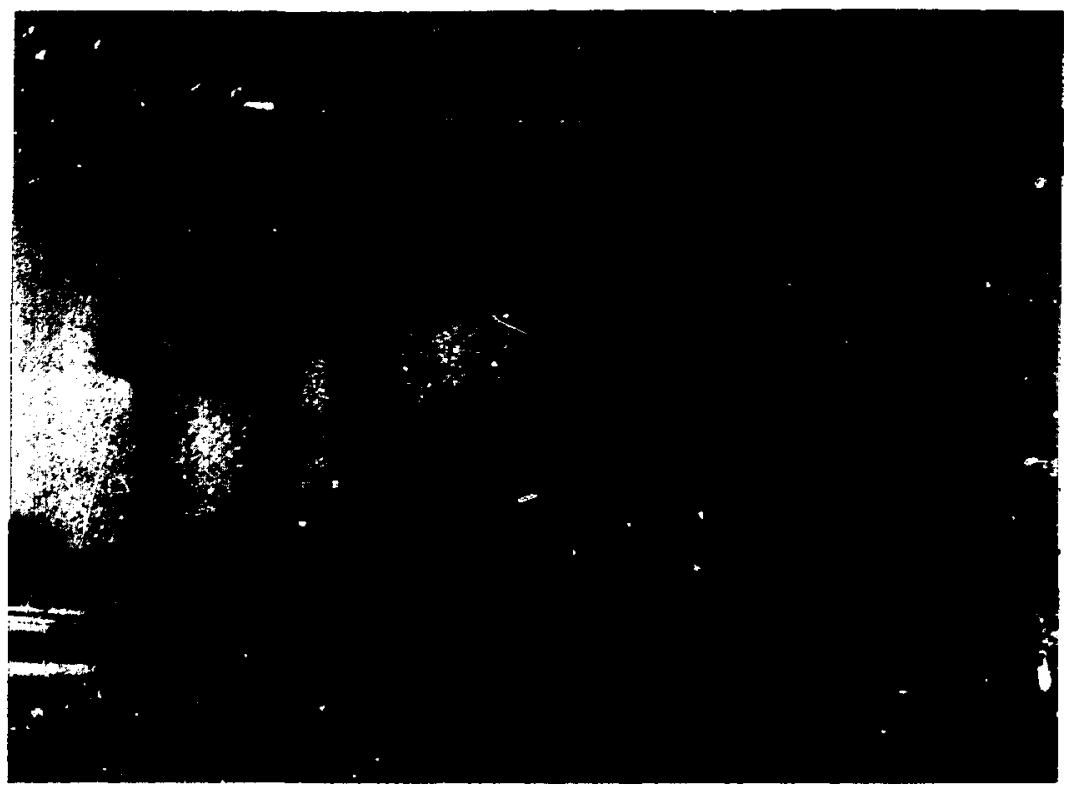

Figure 10. A central-cell-module leg-pair asembly, Iying on its side. The botten of this pair is to the left side of the photo where the two base plates are localed. These base plates will be bolted to the center-vesei support structure. The large plate on the right side (oriented vertically in this photo) structurally joins the two less to provide rigidity in the longitudinal direction. Adding to this longitudinal rigidity are the outboard flanget, at the top akd bottom of the photo, and the inboard flanges between the les plates. These flanges actually form an l-beam within each Ieg. The two horizontal surfaces in the center foreground will be welded directly to the module shell plate. Note that a portion of the ring stiffener in this region was actually made as part of the leg structure.

\section{Center-Vessel Support Structure}

Until the axicell configuration was incorporated, our design for the support structure underneath the central cell was a simple set of concrete piers, much like the end-vessel piers. However. with the order-of-magnitude increase in longitudinal loads generated by the new axicell-magnet geometry, we had to rethink this concept. A change was necessary, primarily, because the bottom of the center-vessel legs were about $5 \mathrm{~m}$ above the vault florr, requiring a rather massive concrete structure to carry the much greater loads down to the foundation. Besides being expensive, this support structure would have occupied much of the space needed for diagnostics, cryogenic piping, and electronic equipment. Thus, we chose to use a steel structure as the most cost-effective alternative.

In the redesign effort. PDM was fortunate to have center-vessel leg-load results from their three-dimensional model. This allowed them to incorporate the various load combinations into hand calculations to evolve both a specific geometry and cross-sectional properties for the new structure.

The center-vessel support structure is actually two separate assemblies that are mirror images of each other, one under the northside 1:ite of legs 


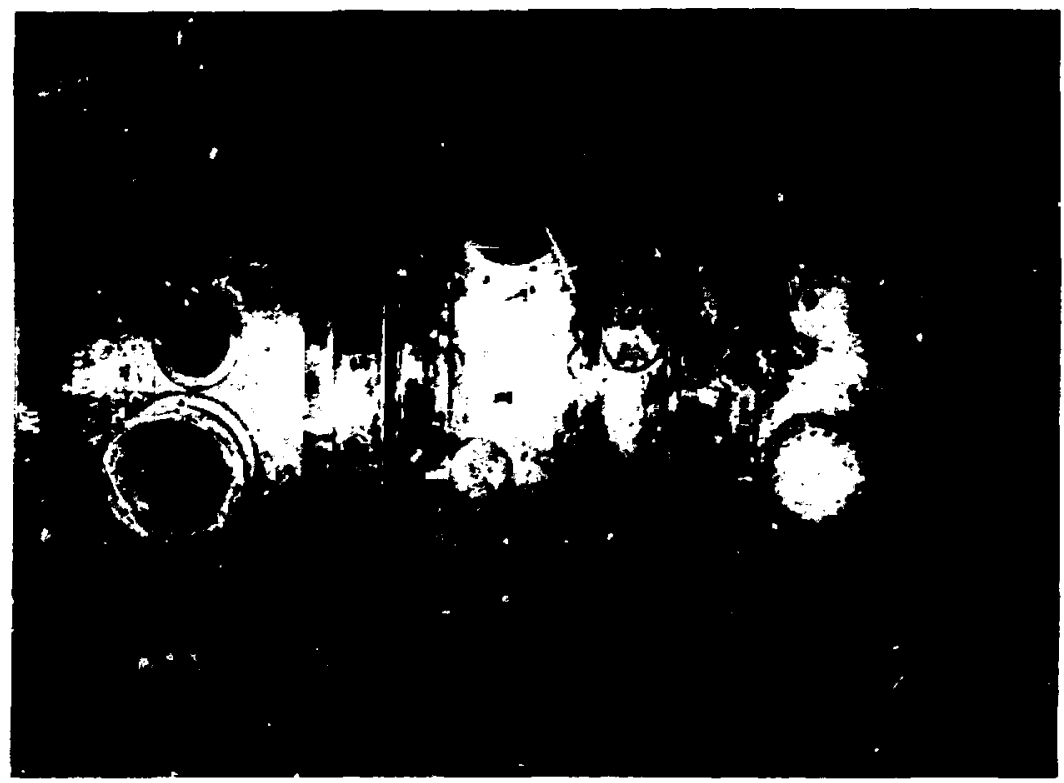

Figure 11. Fiting two central-cell modules to the east transition cylinder. Note the two assembly gaps between the flanges before the shims, bolts, and vacuum bands were installed. Not only did these buill-in gaps allow module alignment, but they also eliminated the need for precise fitting and machining of the mating flanges.

and one under the southside line. Each one consists of a large, fabricated box beam, directly under the vessel legs, that rests on four, vertical, 1-beam-shaped columns (Fig. 12). At each end, heavy cross bracing is placed between the colmns in the longitudinal direction. Also at each Jlumn, a diagonal brace runs in the transverse - irection and carries lateral loads to the floor. The , $3 x$ beam is matro of nonmagnetic stainless steel 1 cause of its large cross section, its closeness to $t$ internal magnets, and its longitudinal direc$t \mathrm{n}$. The remainder of the structure is made of nurmal carbon steel. The entire support structure weighs almost 100 tonnes.

\section{Magnet-Support-Strut Brackets}

The magnet-support-strut brackets are the connecting links between the magnet-support struts and the vessel-stiffening structure. Because of the high loads on the magnets, a great deal of effort went into the design of the magnet-supportstrut attachment points on the vessel. We at LLNL requested that PDM develop a design concept that precluded welds in the load path whenever practical; this ensured that the magnets were supported and restrained by fully inspected parent material.

The general design that we settled on for the vertical and horizontal brackets was a solid round bar with a slot machined in each end to form a clevis (Figs. 13 and 14). The magnet-attachment end had a single hole bored through the bar to accept the pin from the magnet-support strut. The vessel-attachment end had two or three holes bored through the bar so that the bar could be slipped onto the web of a ring stiffener and pinned directly to the web. This meant actually 


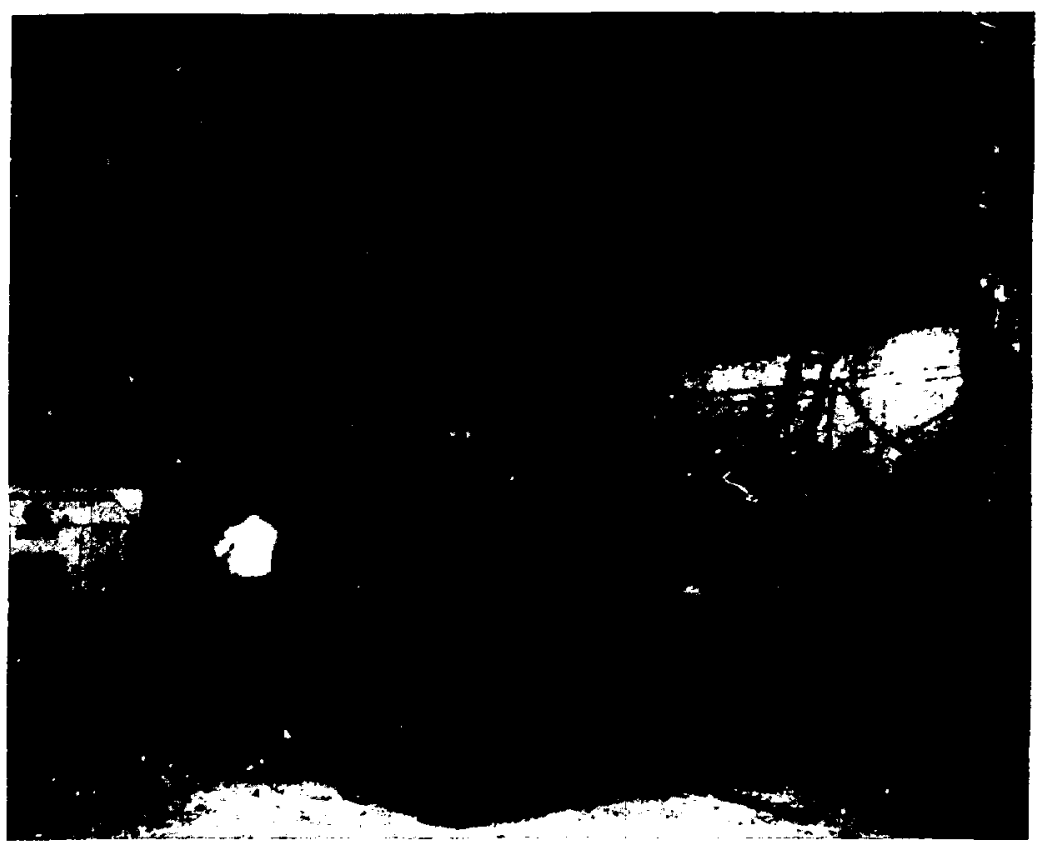

Figure 12. Installing the southside center-vessel support structure. This unit wil: be welded to adjustable base plates that are anchored to the concrete foundation. Then the transverse-direction I-beam braces, which are lying on the floor in the foreground, will be welded diagonally from the box beam to another set of base plates outboard of the vertical I-beam supports. Note that three of the cross-bracing gussels and the box beam are made from stainless steel to break up the magnetic path in the structure in the longitudinal direction. A vertical I-beam support of the northside unit is visible on the right side of the photo.

removing a portion of vessel-shell plate so that the bracket could be joined directly to the main structural member. A vacuum seal was made later using a sheet-metal cup that was welded to the bar and the adjacent shell plate. (At the double ring stiffeners, the vessel end of the bar was pinned to a thick plate that was bolted between the two webs.) There are 56 magnet-attachmentpoint brackets of this design on the MFTF-B Axicell configuration.

The brackets described above reside in the ring stiffeners and, as suck, are designed to react forces only in the transverse plane. To restrain the magnets against the earthquake and magnetic forces operating in the longitudinal direction, PDM evolved a different design concept for these drag-strut brackets. They are each made from two latge plates that are joined, but somewhat separated, to form a clevis inside the vessel where they attach to the magnet-support strut (Figs. 15 and 16). Outside the vessel skin these brackets are attached in various ways to the webs of the two adjacent ring stiffeners and, also, directly to the shell plate. In the center vessel, each of these drag-strut brackets is in line with the column of longitudinal vessel stiffeners and forms part of 


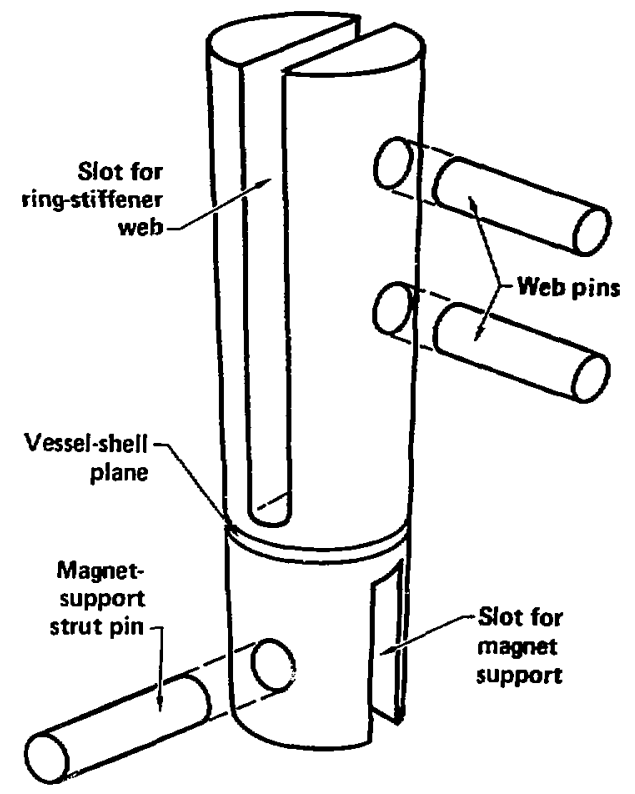

Figure 13. A schematic of a typical magnet-support-strut bracket that attaches to a ring stiffener. This assembly is slipped through a hole cut in the vessel shell plate and is positioned in the location shown by the vessel-shell plane between the two slots. The upper portion of the bracket is double pinned to a circumferential ring stiffener, and the rod end of the eragnet strut is pinned to the lower portion. The strut and web pins are held in place with cotter pins, completing a structural assembly that has no welds in it.

that end-to-end column. These drag struts react forces along a line-of-action that is not entirely longitudinal. Therefore, at the vessel surface, there is both a radial and longitudinal component of force. The two adjacent ring stiffeners react the radial component. The longitudinal component is shared by the shell plate and the longitudinal stiffeners. Some of these 16 drag-strut brackets carry loads as high as 350 tonnes.

\section{Vessel-Shell Penetrations}

To provide access to the interior, the vessel skin has about 500 penetrations, or ports. Most of these are circular, with diameters ranging from 5 to $203 \mathrm{~cm}$ (Fig. 17). All ports, except for the smallest ones and the ones located in very thick sheil plate, are reinforced with a washer-shaped doubler plate welded to the vessel skin around the port circumference (Fig- 18). A number of penetrations are rectangular in shape, and some are as large as 120 by $210 \mathrm{~cm}$ to allow installation and removal of large pieces of equipment. Many of the largest circular ports carry loads up to three tonnes. Every vessel penetration is sealed with standard O-rings. 


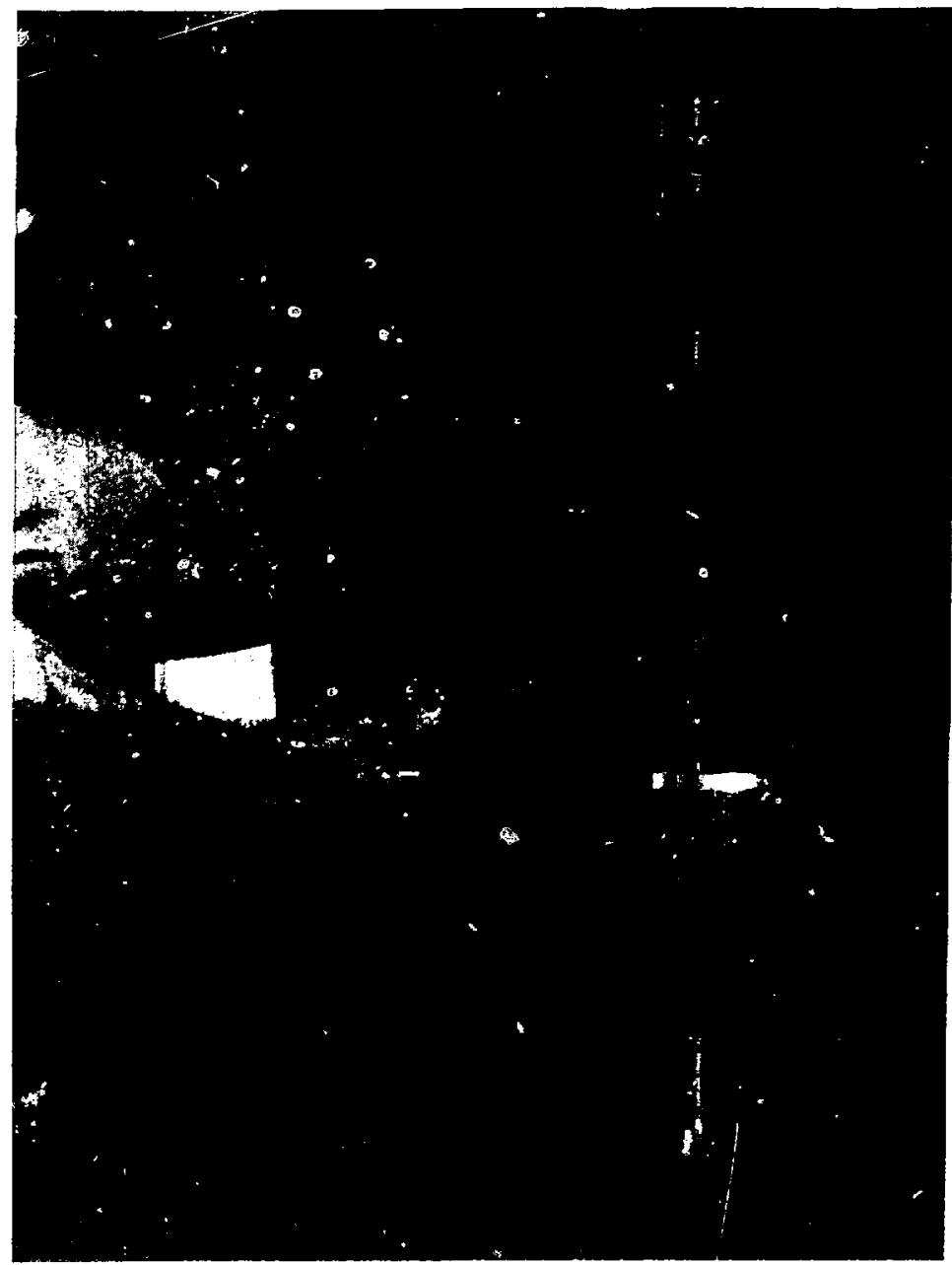

Figure 14. One of the vertical magnet-support-strut brackets with a vacuum-sealing cup over the stainless-steel bar. The upper, round surface of the steel cup will be welded directly to the inside surface of the vessel-shell plate; the inner hole of the cup part, not visible in this photo, is welded to the bar. Thus, a vacuum seal, flexible enough to accommodate some movement of the magnet, is created between the support bar and the vessel shell. 


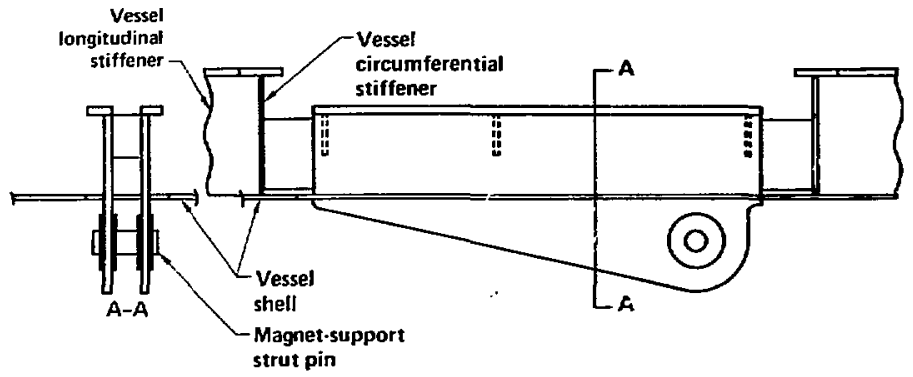

Figure 15. A schematic of the yin-yang drag struts that react the longitudinal earthquake and magnetic loads. The clevis is formed by two thick plates (seen in cross section in a view A-A) (hat are held in the correct position by the vessel shell plate. In the right-hand sketch, the magnet strut would be attached at the pin hole and would extend down to the right at about the same angle as the lower edge of the bracket. The vertical component of this strut load is reacted by the two vessel circumferential stiffeners to which the bracket is welded. The longitudinal force component is primarily reacted by the vessel shell.

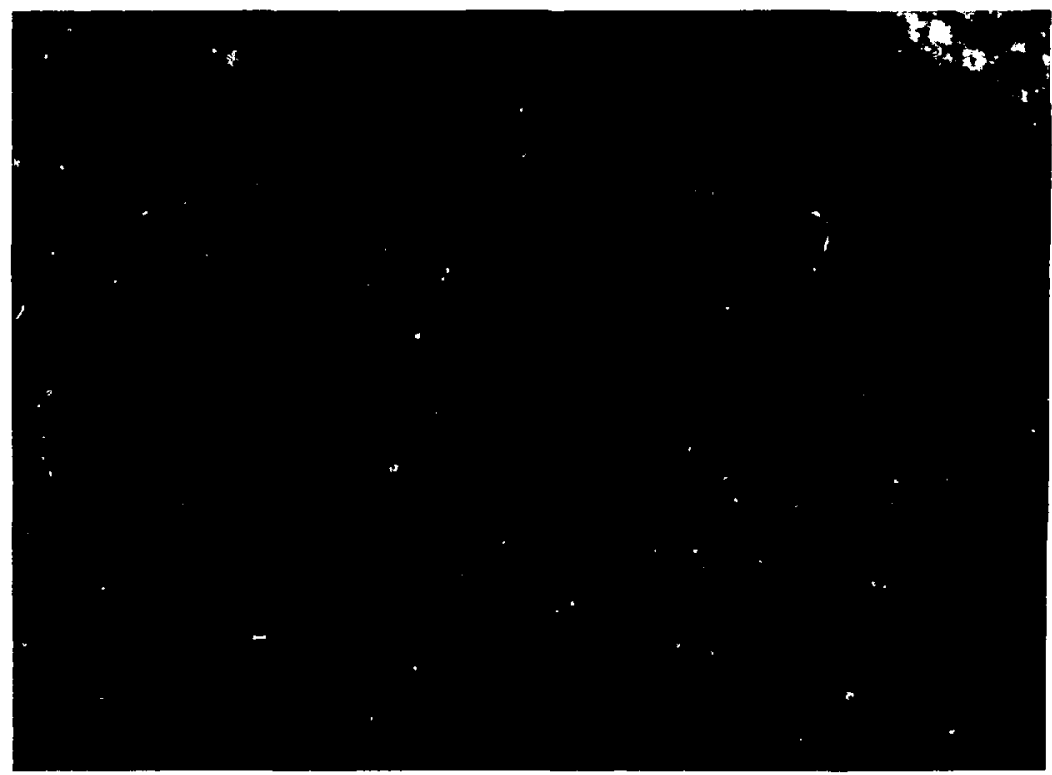

Figure 16. One of the drag-strut brackets from the transition region. This very stout structure is made of stainless-steel-plate material. The top horizontal surface in this photo becomes part of the vessel shell. The two thi:k vertical clevis plates are continuous from the top pin joint to the flanges at the bottom. For reference, this bricket is turned upside down when compared with the schematic in Fig. 15. 


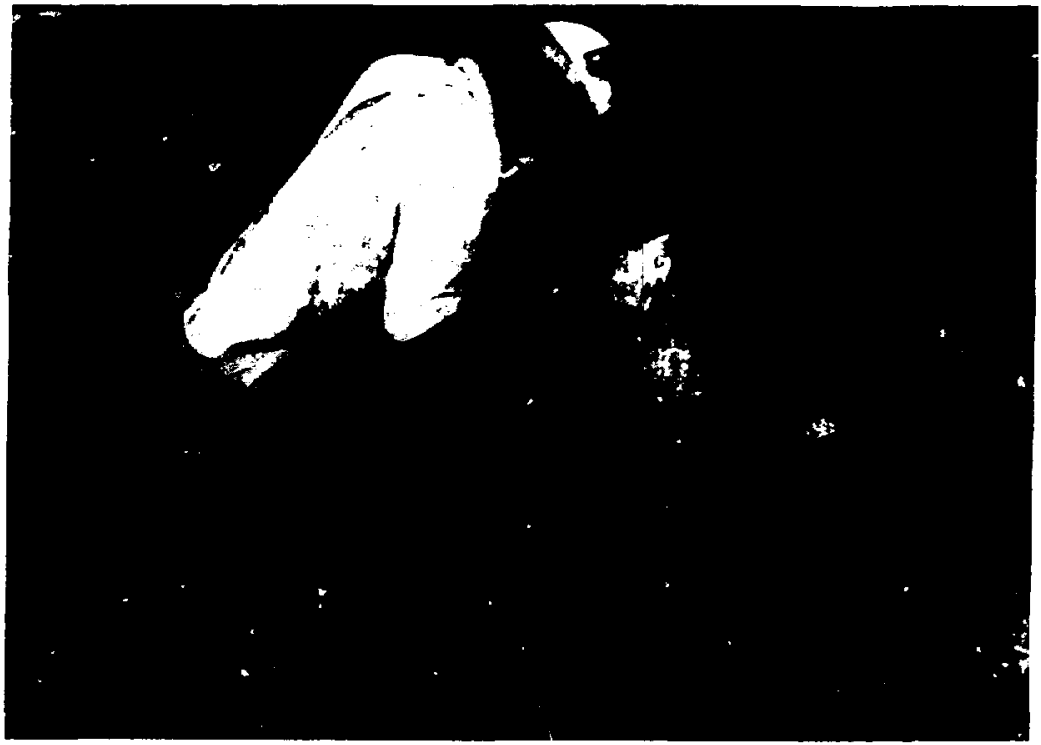

Figure 17. Weld preparation work on a typical vewel port. As shown by the slanted intersection, this port will be installed in 2 nonradial orientation to the vessel skin. Becruse many of these ports require precise alignment relative to vessel datums, PDM fabricated special alignment fixtures for the inslallation and inspection process. 


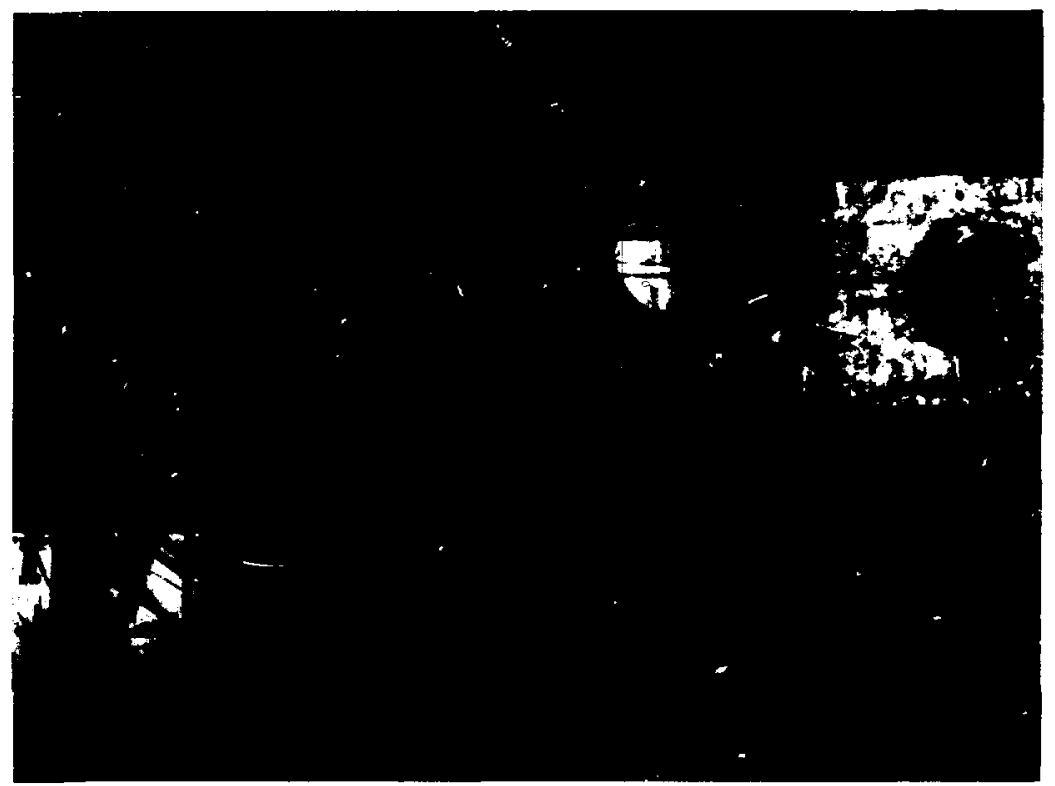

Figure 18. A typical doubler plate welded to the vessel skin before installing the penetration. The size of these plates depends on the underlying shell thickness, the penetration diameter, and the load that will be carried by the penetration. 


\section{Construction of the Vacuum Vessel}

\section{P'. t and Field Fabrication}

The vacuum-vessel manufacturing process began in early 1982 with the arrival of the Type304 stainless-steel material at PDM's plant facilities. All vessel components were fabricated at these locations and at several subcontractor sites. Because shop work tends to be more efficient than field rork, and therefore more economica! we built the subassemblies in the largest possible pieces at these plants and then shipped the pieces by truck or railcaz to the construction site at LLNL.

The first step in the fabrication process was polishing the inner surface of all of the shell plate to facilitate clerning the finished vacuum vessel. Next, the shell plate and the flanges were rolted to the correct radius. After cutting and preparing edges for welding the subassembly pieces vere fitted and welded together. Because mosi of the major MFIF-B subassemblies are cylinders or cones that are too large in diameter to ship completely assembled, PDM fabricated each of them i: three or four sections with the remaining longitudinal seams to be made in the field. Each section consisted of the curved shell plate with the matching portions of the ring stiffeners welded on the ouler surface (Fig. 19). Other fabricated components included 36 vessel legs, 4 neutral-beam domes, 4 midsection plates, about 400 vessel-shell

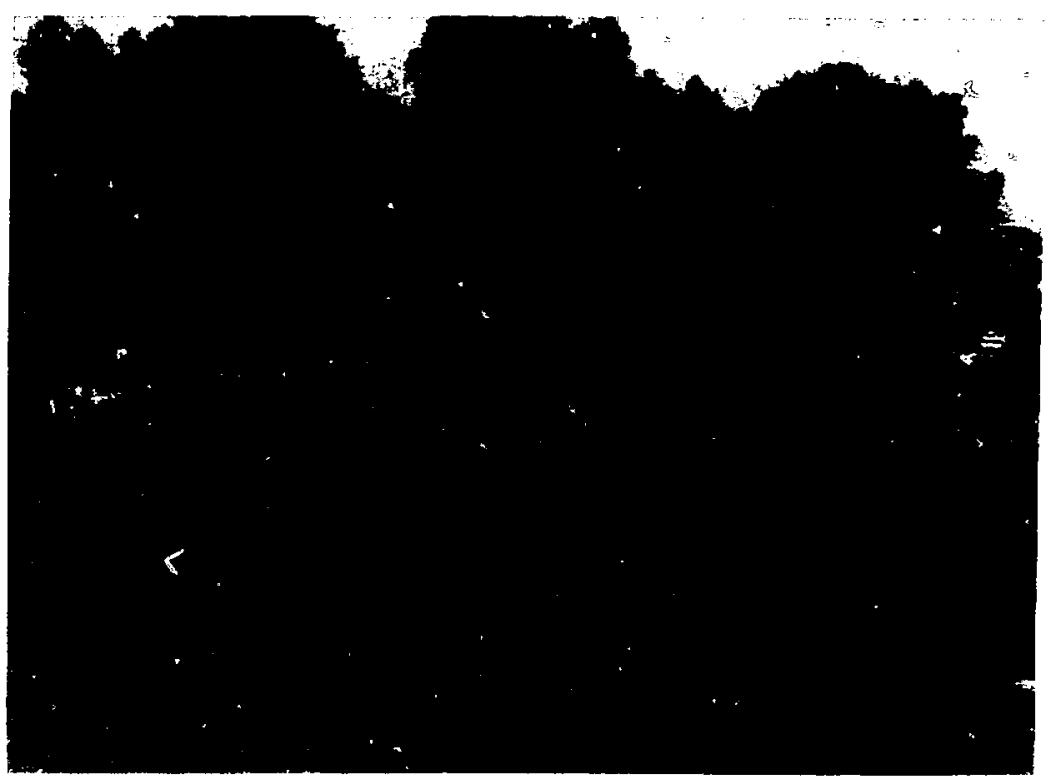

Figure 19. Three sections of shell plate as they arrive crom the fabrication plant. These three subassemblies will be fitted together and welded to form a central-cell module like the one in the background. Notice that the ring stiffeners are already welded on arrival. Parts of ring stiffeners are missing on these sections because those portions are built into the leg assemblies (see Fig. 10). 
penetrations, 72 magnet-support-strut brackets, 2 center-vessel support structures, numerous longitudinal stiffeners, and a multitude of smaller parts.

As the circular sections arrived in Livermore from the PDM plants, they were carefully fitted and welded together. We used precise surveying techniques and equipment to ensure that we met the exacting alignment requirements of the final vessel assembly. Additional components, such as magnet-support-strut brackets and penetrations, were welded in place before moving each completed cylinder the short distance from the fabrication site to the erection area inside the vault (Fig. 20). In this way, PDM assembled two westend-vessel cylinders, two transition cones, two transition cylinders, and six central-cell modules.

\section{Assembly in the Vault}

Inside the vault, LLNL built the reinforced concrete foundations to which the vacuum vessel support structures were secured. The west vessel foundation is geometrically similar to the foundation for the east vessel, but it is more highly reinforced to be significantly stronger. This foundation consists of four piers directly attached to a thick, underlying concrete mat. Embedded in the top of each pier are two adjustable base plates to which the vessel legs are welded. The central-cell foundations are two separate, reinforced mats, each with mounting plates for center-vessel supportstructure attachment. We split the central-cell foundations because there is a large buttress or shear wall across the lower, center vault; this buttress

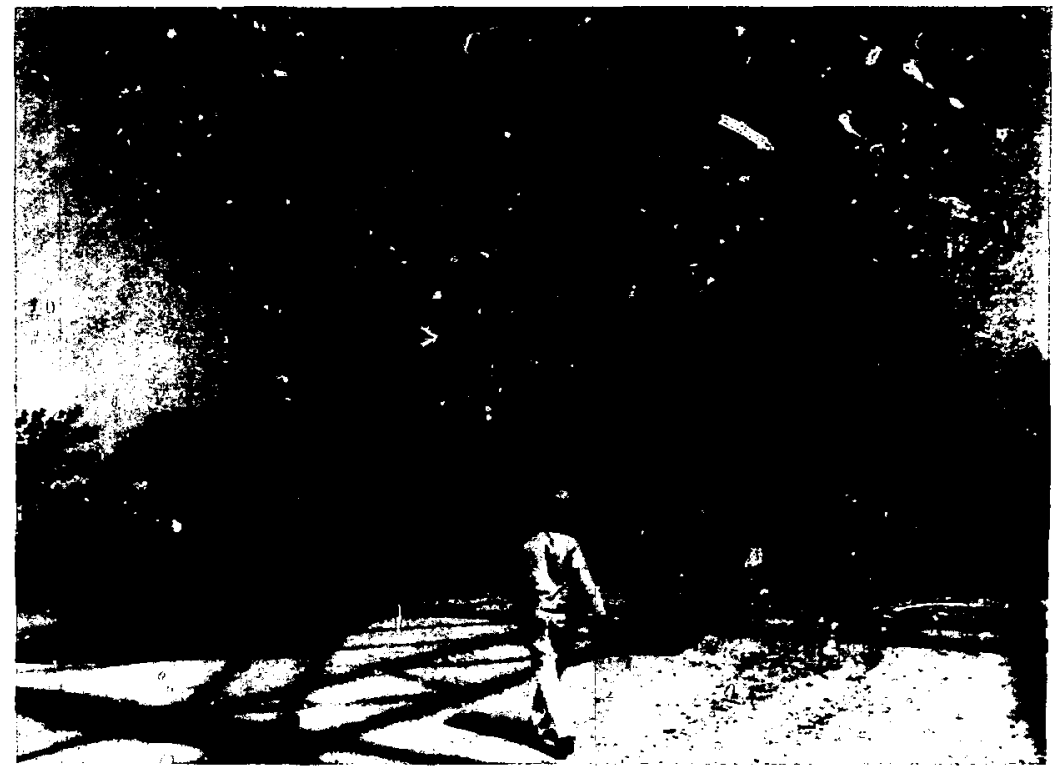

Figure 20. Moving one of the 50 -tonne west-end-vessel cylinders from the fabrication site to the vault erection area. We rented two large truck cranes to move and place these $12-m$-diameter assembiies under the building's bridge crane. 
stabilizes the 23-m-high side walls. (Figure 9 shows the above features.)

The erection sequence developed by PDM meshed with sur demanding and changirs project schedule at LLNL. (The PDM teams were constrained in their planning by the 55-tonne capacity of the vault bridge crane.) Their work inside the vault hegan by setting the west-end-vessel legs in place and welding them to the steel base plates on the piers. Next, the two, 10.6-m-diameter wist-vessel cylinders were mounted on the legs. These two cylinders were joined with four, equally spaced, curved plates called midsections, which already had longitudinai stiffeners welded onto them (Fig. 21). Then, the four neutral-beam domes were welded between the two cylinders at the vessel top, bottom, and sides (Fig. 22). All of these erection operations required careful fitting and measurement to meet LLNL's tritericn for centerline alignment of the vessel within a $5-\mathrm{cm}$ diameter circle over the entire ressel length.

Next. PDM erected the east and west transjtion cones. These cones provide the geometry for changing from the larger end vessels to the B-mdiameter central cell. These cones are welded directly to the inboand portion of the end-ressel cylinders (Fig. 23). The center-vessel support structures were :hen assembled and welded to the fotindation base plates (Fig- 24). This allowed the 28 center-vessel legs to be bolted on the stainlesssteel box beams (Fig. 25). The last welded structures, the east and west transition cylinders, could

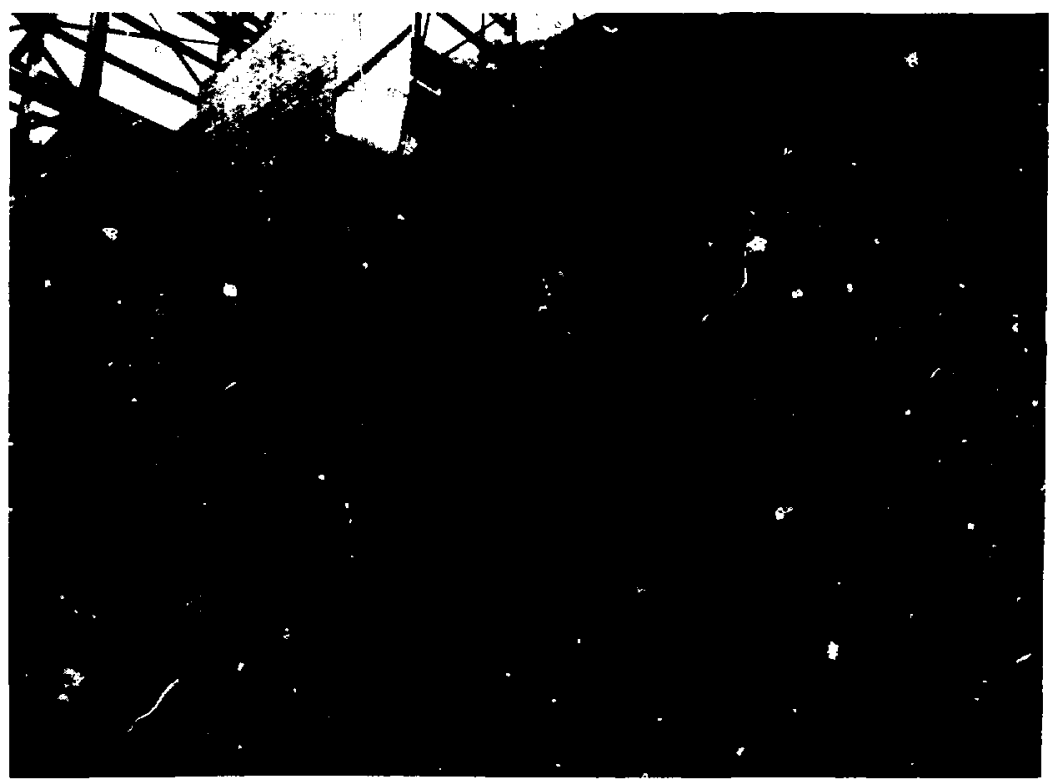

Figure 21. Moving one of the four west-vessel midsection plates into the vault using the building's bridge crane. The two west-end-vessel cylinders welded to their supporting legs are shown in the background. This 50-mm-thick midsection plale, with ito longitudinal stiffeners in place, will be fitted and welded between the two cyliaders at one of the 45-deg-from-horizontal points. 


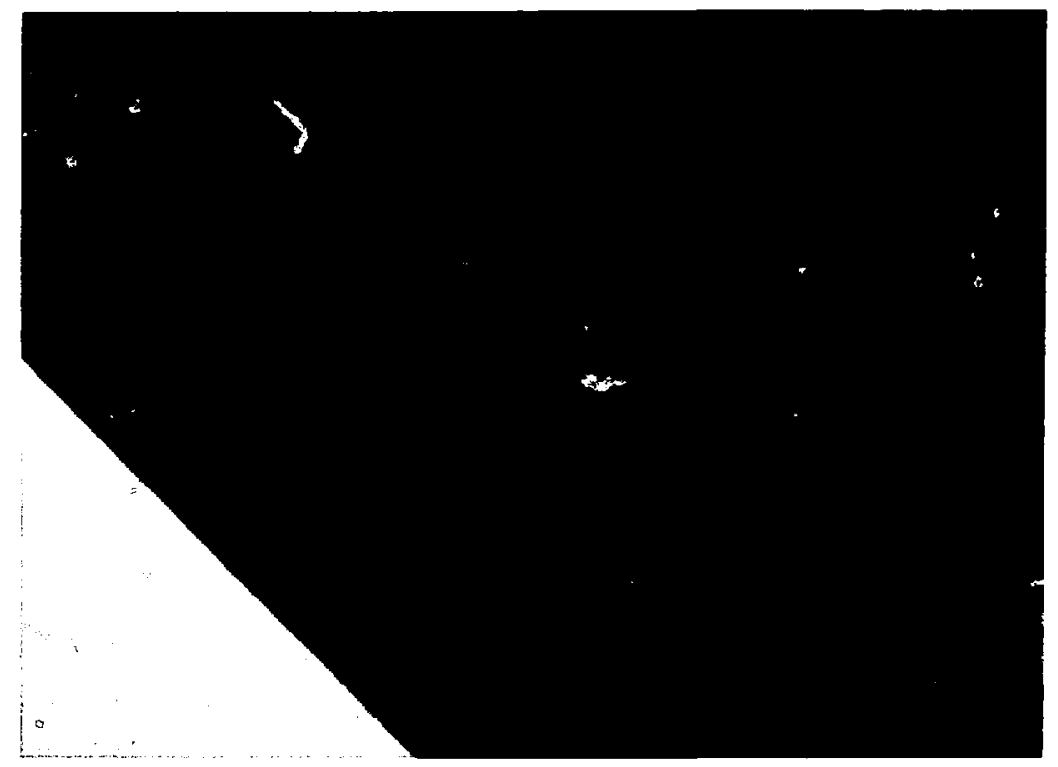

Figure 22. Lowering the top neutral-beam dome into place on the west vesel. Very precise aliganat work ensures that the center of the beam done'n spherical surface is on the veasel centerline and at the proper longitudinal location.

now be installed. They were welded to the transition cones at one end and the outermost set of center-vessel legs on the other end (Fig. 26).

The last vacuum vessel structures that we erected were the six removable center-vessel modules. Each of these cylinders, in turn, from the east to the west, was fitted in place, carefully aligned, and welded to its legs. When the modules were in final position. PDM measured the local gap at each of the 624 flange bolts in the first 6 joints. Custom shim blocks were then machined for installation at final assembly tine. The last joint, with 128 shims, was left unmeasured until final assembly so that slight adjustments could be made. These six modules were then moved to the magnet assembly yand for installation of the centralcell solenoid magnets. 


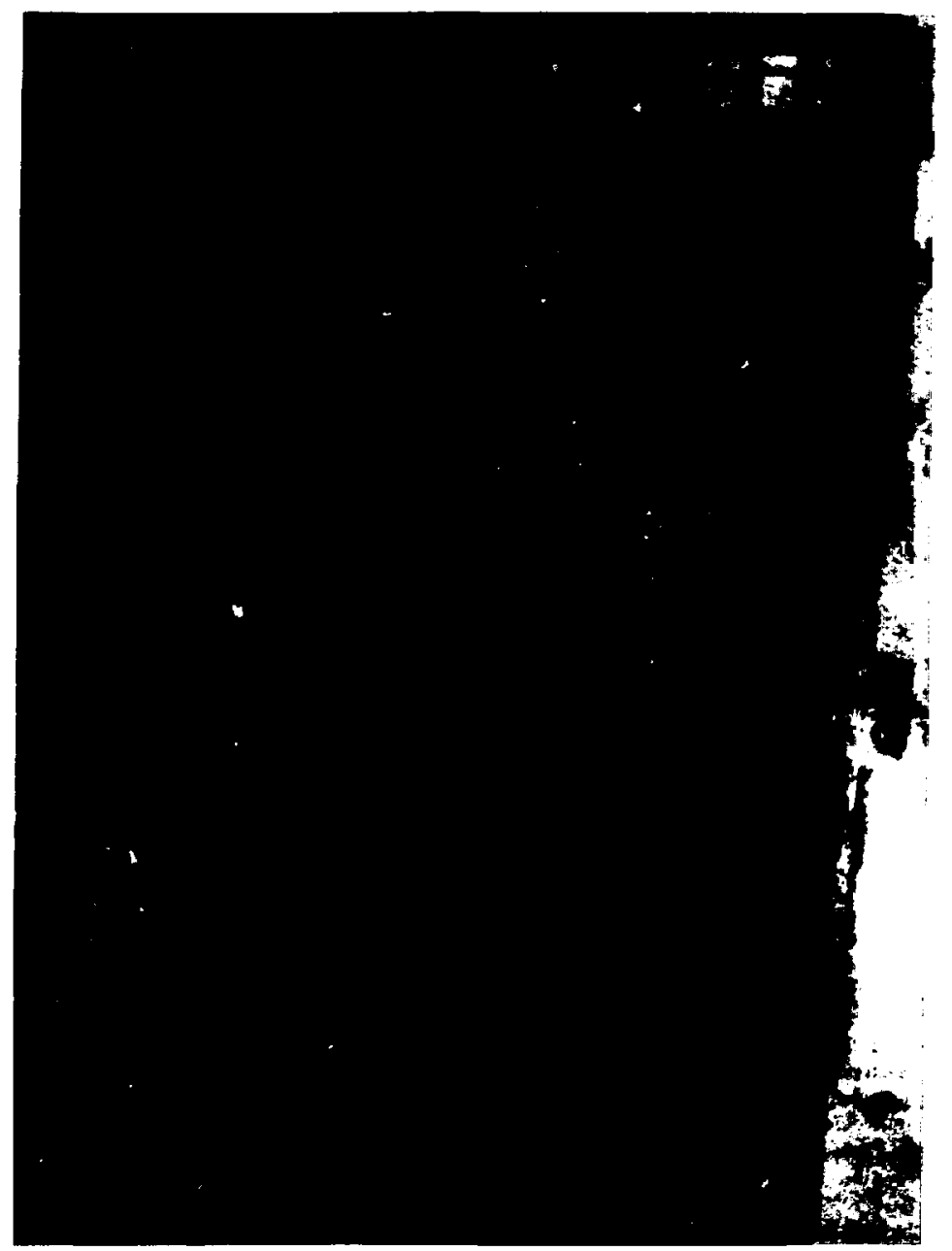

Figuse 23. Installing the east-end-veweel transition cone. This was one of the first operations during the extensive modifications to the existing MFTF vacuum vessel. 


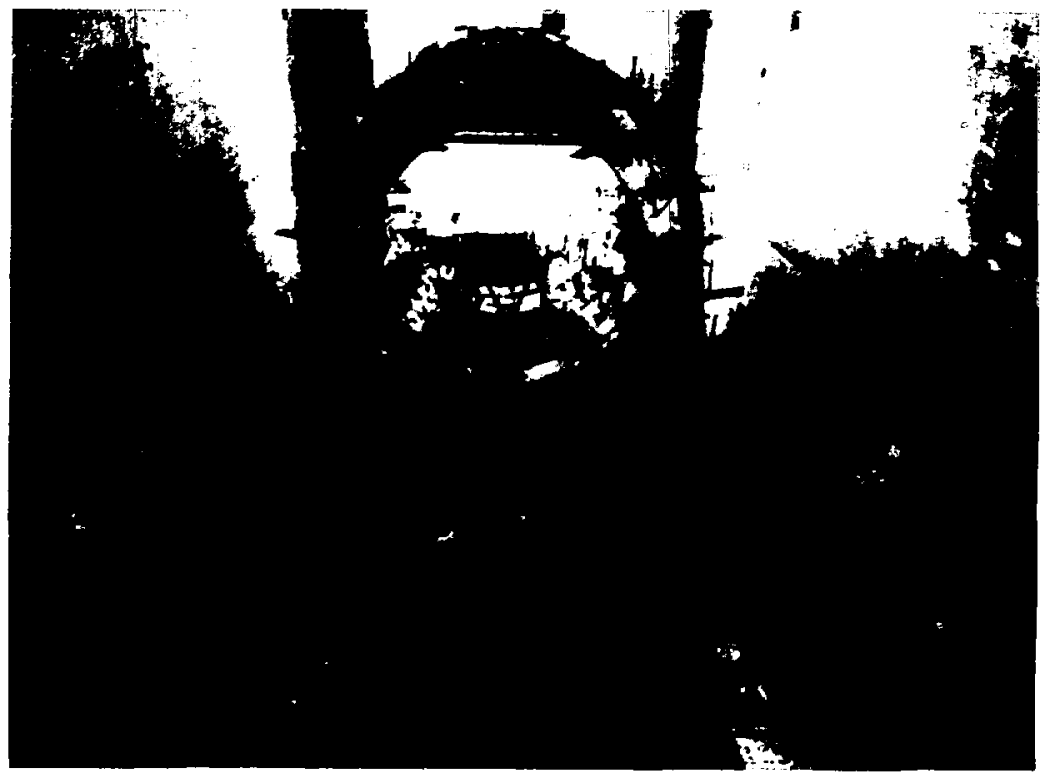

Figure 24. A view looking west from the top of the east vesse], showing the newly installed center-vesse] support structures in the foreground. Notice that plates are welded to the top of both box beams where the central-cell-module legs will be bolted. 


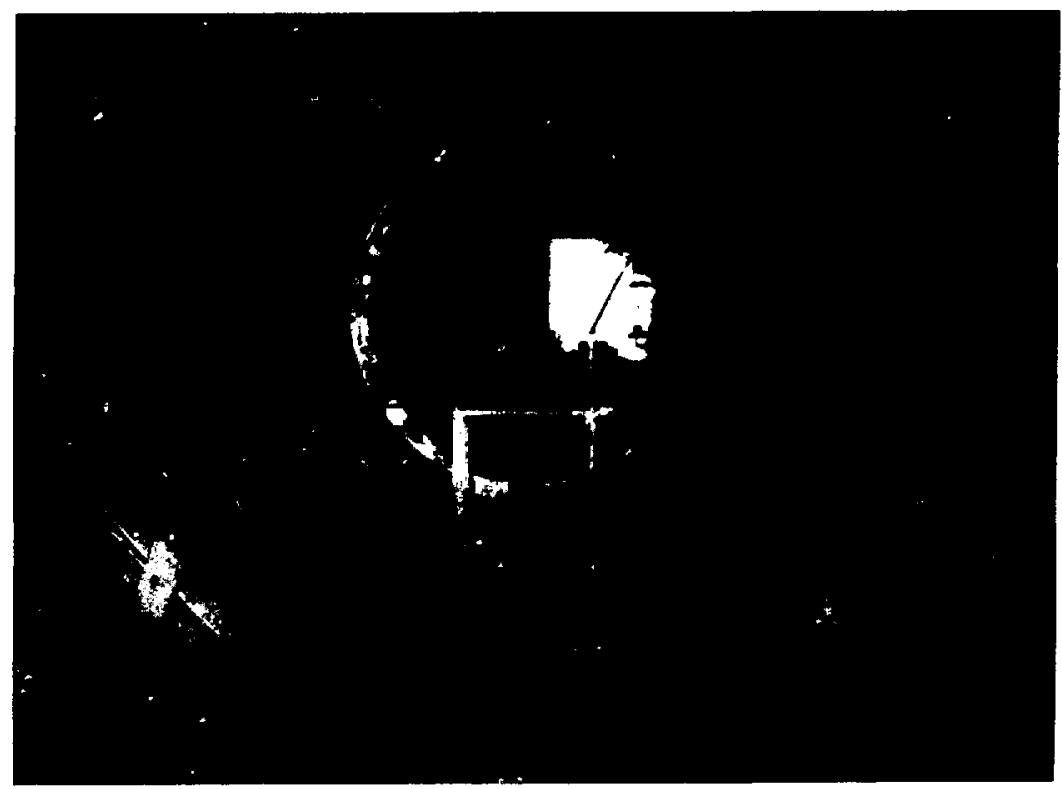

Figure 25. The central-cell legs bolted in place on the center-vessel support structure. The single legs on each side in the foreground will support the transition cylinder. The double-leg assemblies (see Fig. 10) behind them will be joined to the six central-cell modules. 


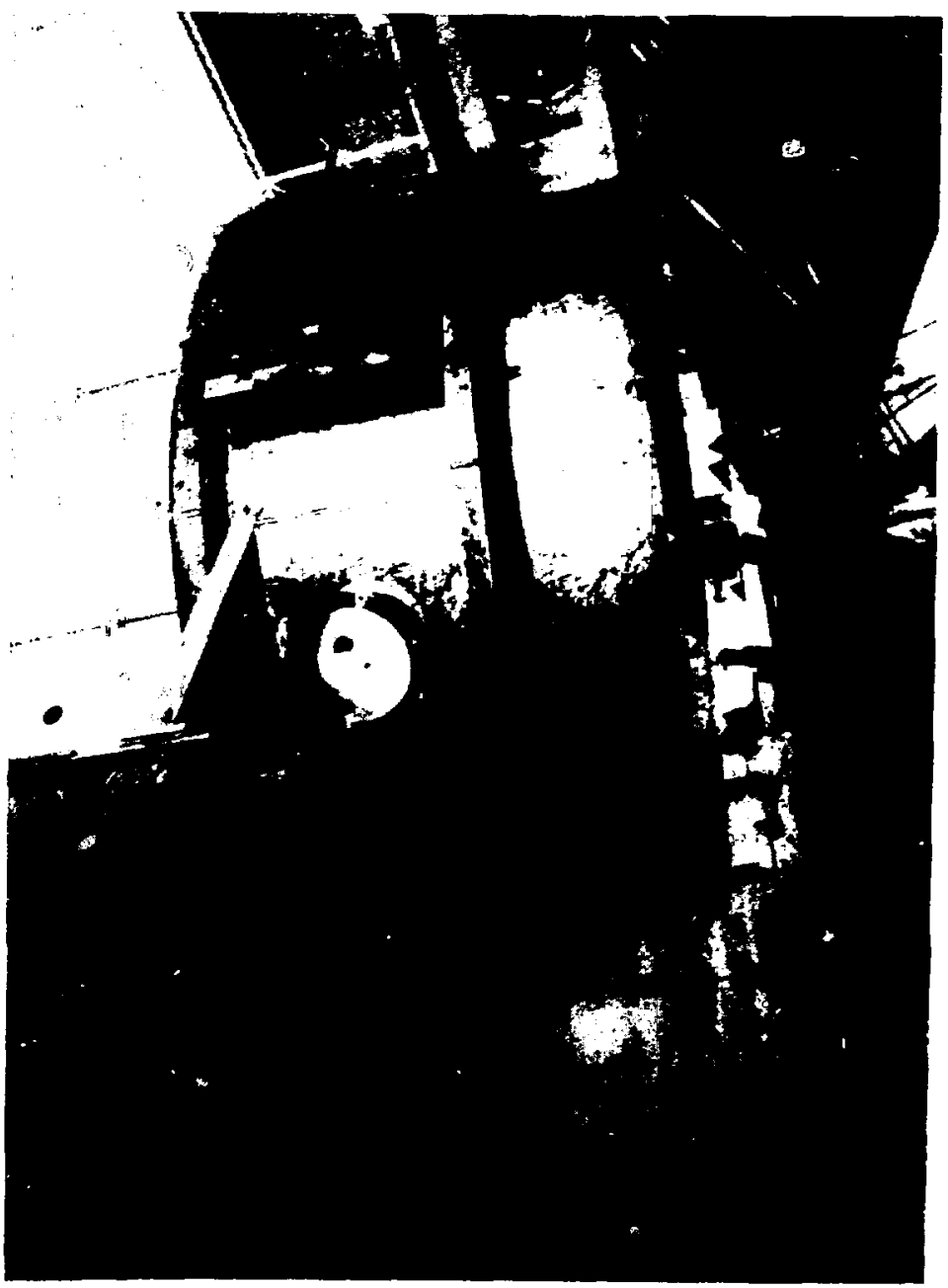

Figure 26. Installing the east transition cylinder on the transition cone and single Iegs. The lateral diagonal bracing of the center-vessel support structure is located in the left foreground. 


\section{Acceptance Testing of the Vacuum Vessel}

\section{Vacuum Integrity}

As part of our final acceptance tests, we had PDM perform a vacuum leak test on each of the eight sections of the vessel. To do this, PDM designed and fabricated three, spherically-shaped, carbon-steel test heads. These heads are $8 \mathrm{~m}$ in diameter and fit all of the modules and both transition cylinders (Fig. 27). On completing the field fabrication of each module, PDM mounted two of the test heads and checked the vacuum integrity of that individuai module (Fig. 28). With the third test head and an end dome, leak checks were run on each of the completed end vessels (Fig. 29). Later, we conducted the first pumpdown of the completed vacuum vessel with high confidence because we had followed the above procedure and, consequently, had tested everything but the seven welded intermodule vacuum-seal bands.

\section{Geometric Integrity}

The extensive acceptance test procedure for the vacuum vessel included verifying every important dimension on the finished vessel. Features that were checked by PDM and LLNL were as follows:

- The vessel centerline alignment. bracket.

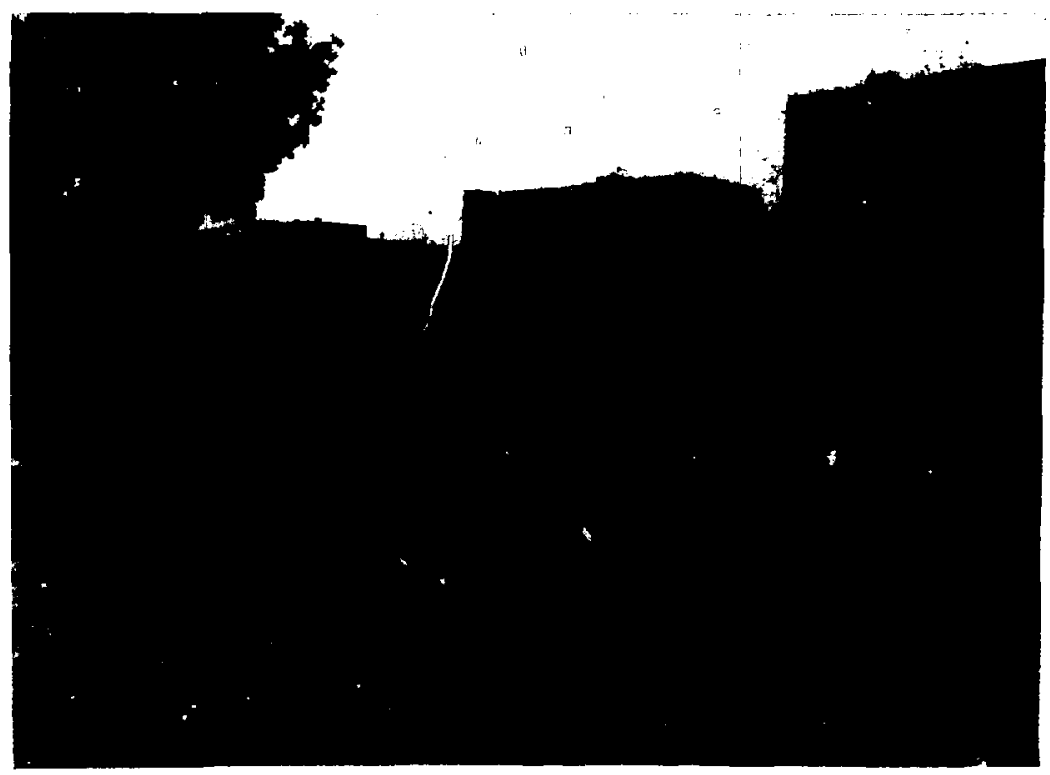

Figure 27. One of three carbon-steel test heads. These 8-m-diameter heads fit the six modules and the two transition cylinders. 


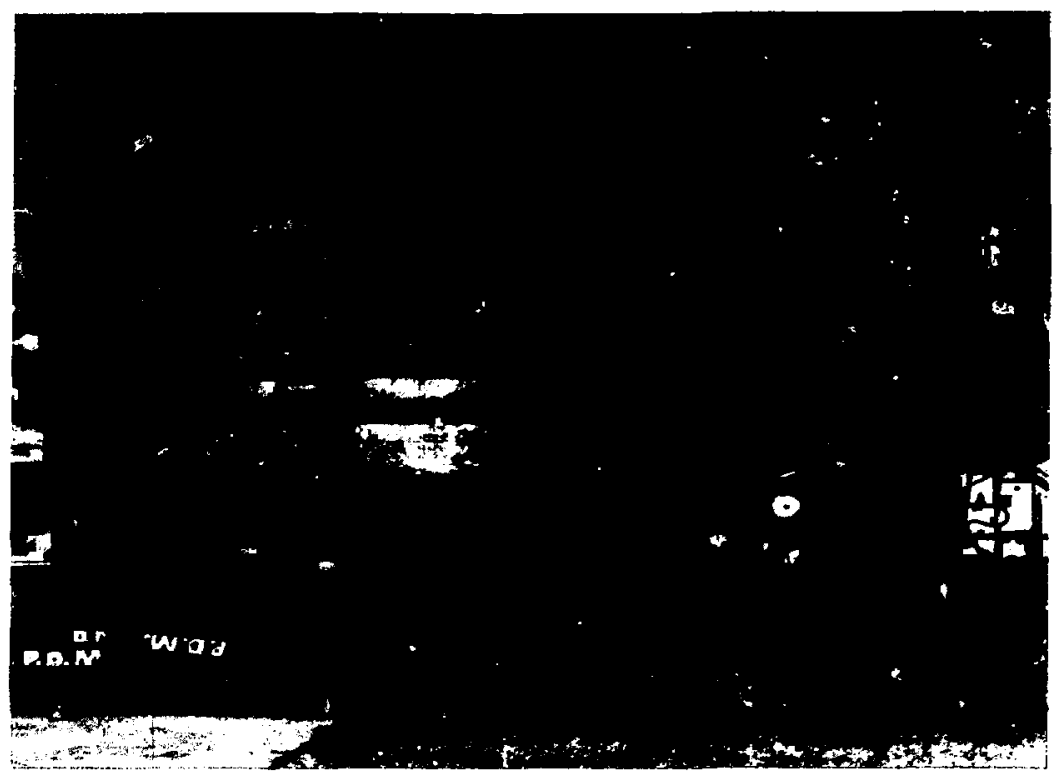

Figure 28. Vacuum testing a central-cell module. The carbon-steel test heads are welded to the module flanges with vacuum bands that are similar to those that will be used for the final module assembly. The diffusion pump is located on the right side; it is used to obtain a vacuum in the $10^{-6}$ Torr range.

- The location of all ports.

- The aiming of certain critical ports.

- The location of numerous mounting pads and brackets.

These data have been combined to form a two- volume acceptance-test report. Additionally, PDM produced a complete set of as-built drawings. With the vacuum leak test information and the material certifications, this package forms a comprehensive record of the existing vacuum vessel. 


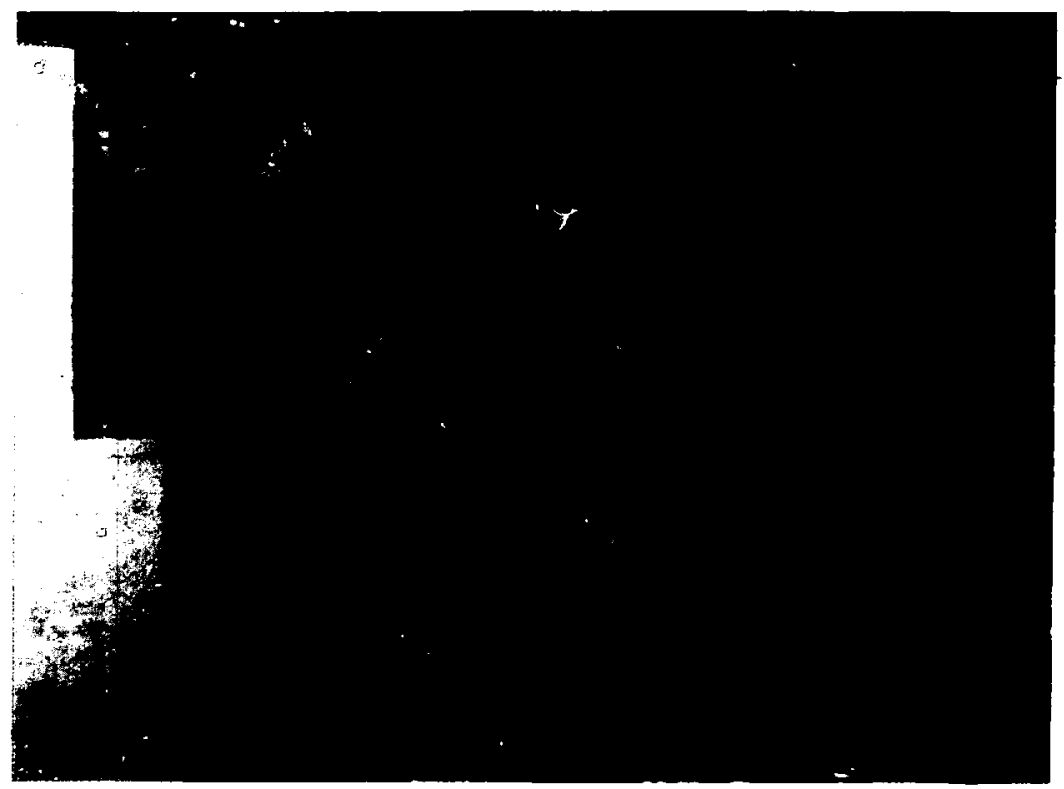

Figure 29. In the background, the east vessel is being vacuum tested, while in the foreground, a central-cell module is being installed.

\section{Preparation for the Integrated Engineering Tests}

\section{Magnet Installation and Center-Vessel Reassembly}

The tandem Mirror Fusion Test Facility was a line item in the Congressional budget and is scheduled for completion in June of 1986, although LLNL plans to accomplish all milestones early in 1986. Our final tasks for this project are assembling the machine and then conducting a series of engineering tests to verify that the operational requirements of the system are met. We have called this test series the Integrated Engineering Tests.
Assembly of the machine started in December of 1984 with installation of the magnets into the vacuum vessel and reassembly of the centervessel modules. There are a number of variations in the order in which these tasks could be performed, but we were constrained by the availability of the new magnets for the axicell configuration. First, the yin-yang magnets were moved into their respective end vessels through the open, outboard ends. Next, the transition magnets were installed using the building crane to lift them into the central-cell region and move them outward through their transition cylinders into the end 
vessels. These transition magnets were followed, in the same manner, by the axicell magnets.

With the above work completed, the centervessel modules could be reinstalled. Remember, they had been transported to the magnet assembly yard where two solenoid magnets were hung in each module (Fig. 30). The trip back to the vault was made on a special low-bed trailer (Fig. 31). The building crane then lifted each module over the west vessel and placed it on the center-vessel support structure (Figs, 32 and 33). Shim blocks and bolts were installed in each gap, and the module legs were bolted to the box beams of the center-vessel support structure. With all modules reinstalled, the seven vacuum-seal bands were welded in place. This completed the vacuum- tight, welded envelope that ran from end dome to end dome.

\section{Vacuum Integrity Testing}

The vacuum integrity requirement for the total vessel system is a helium-gas leak rate of less than $1 \times 10^{-6}$ Torr $\cdot \ell / \mathrm{s}$. To demonstrate this level of performance, we began the first pumpdown of the entire MFTF-B vacuum vessel on October 1 , 1985. This was also the beginning of the Integrated Engineering Test series. Currently, in midOctober 1985, we are systematically checking each of the $\mathbf{5 0 0}$ penetrations, 7 center-vessel vacuumseal bands, and 2 end-dome seals. Our procedure

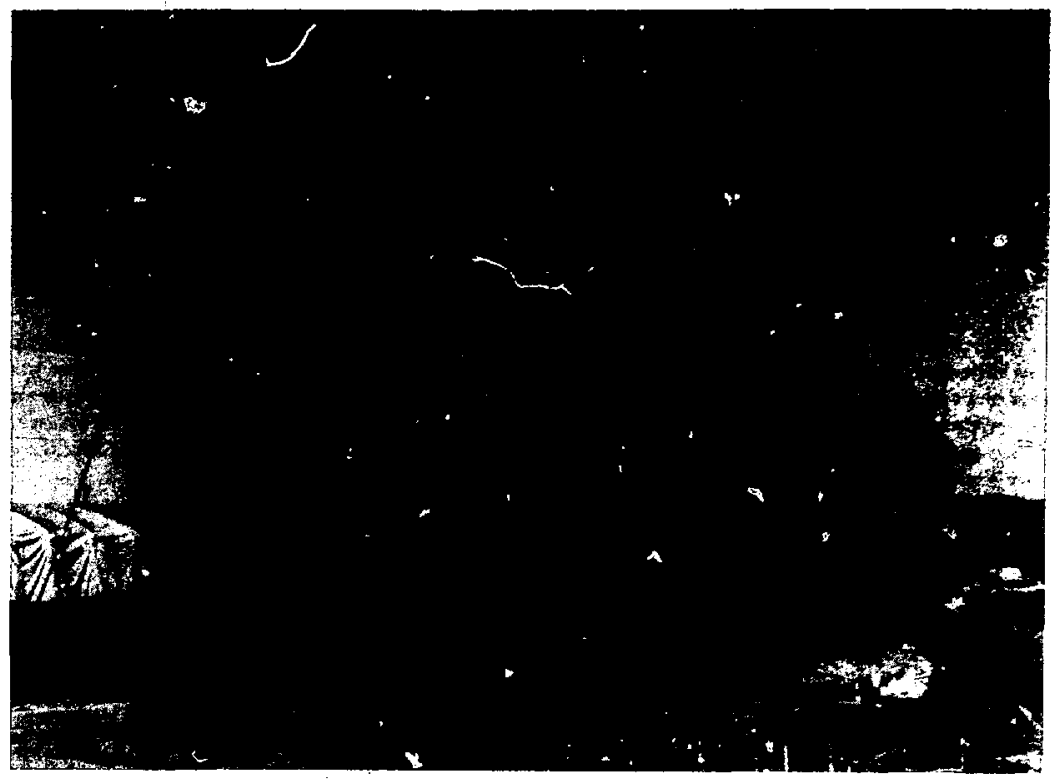

Figure 30. Four of the central-cell modules in the magnet-assembly yard. Each module contains two 5-mdiameter solenoid magnets. The specially-designed vapor-cooled current leads are shown on top of three of these modules. These leads provide the connection between the 4.5-K magnet conductors and the ambient temperature power lcads. 


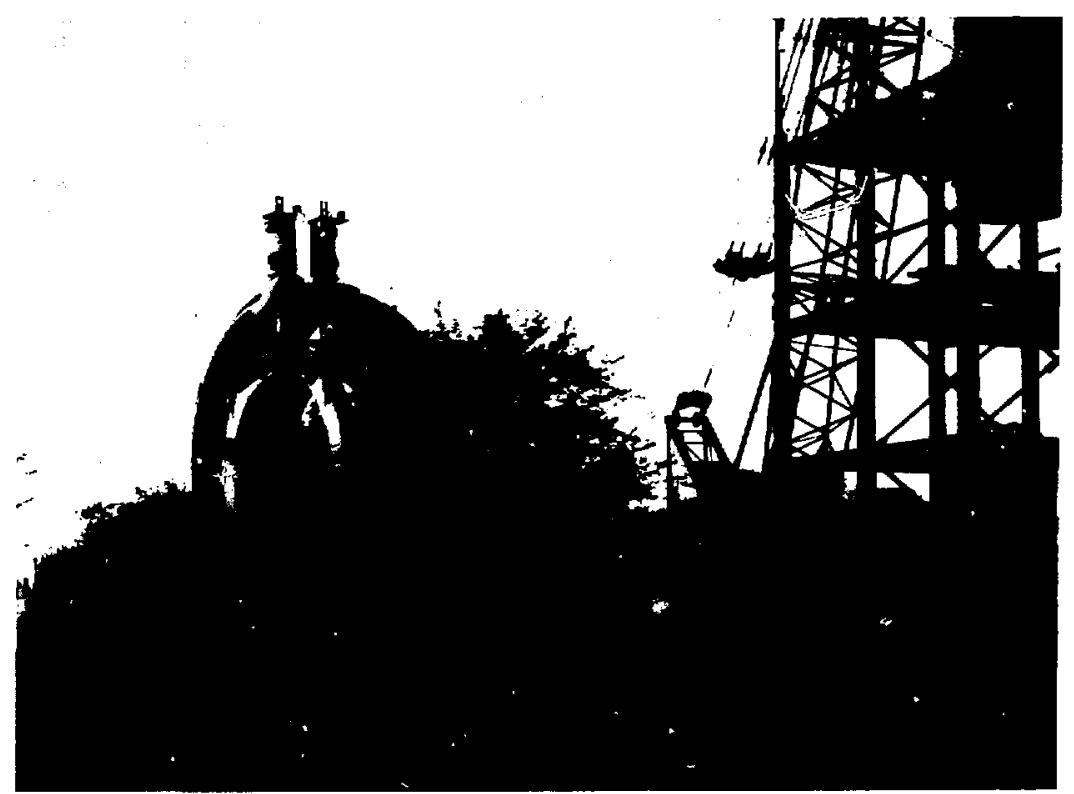

Figure 31. Moving a central-cell module for final installation in the vault. The special low-bed trailer helps stabilize this high-center-of-gravity load, and the steerable rear portion provides the maneuverability for turning corners and getting underneath the building's bridge crane.

is to introduce helium into a plastic bag that is taped over the item, or part of the item, and read the response on a calibrated mass spectrometer connected to the vessel interior. The leak rates for every feature will then be summed to verify the total leak rate of the vessel.
Two views of the entire MFTF-B vacuum vessel with its extemal components in place are shown in Figs. 34 and 35. These photos were taken about a month before the integrated engineering tests began. 


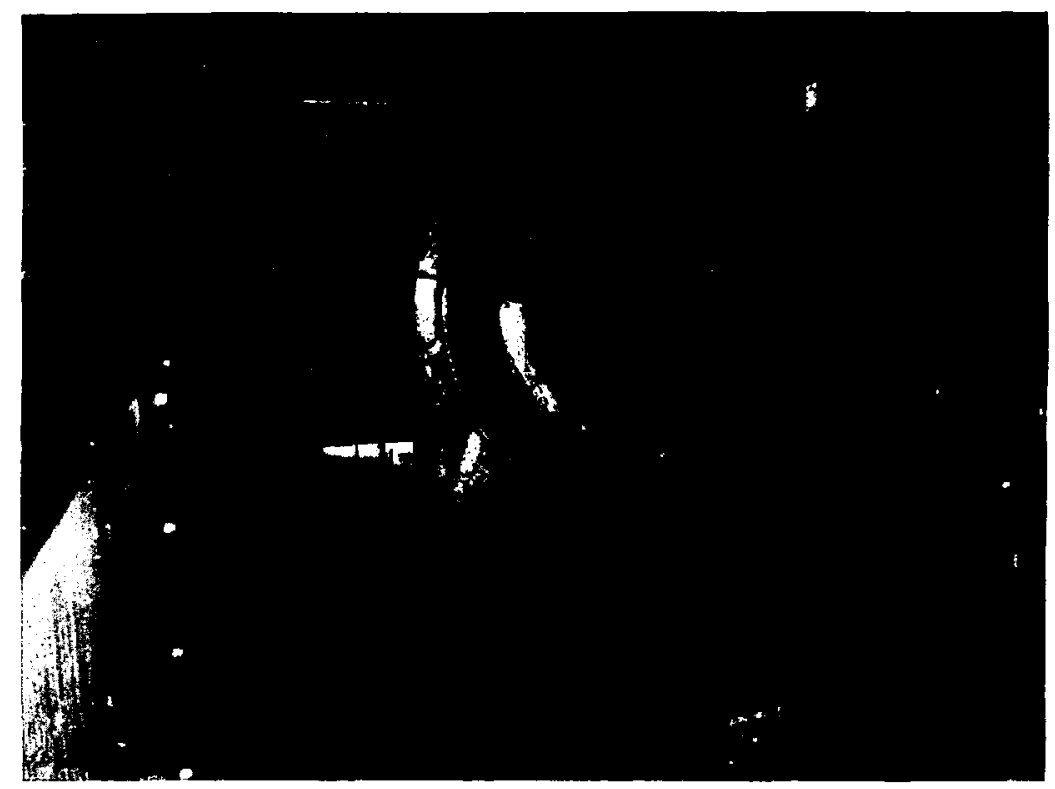

Figure 32. Lifting the central-cell module over the west vessel using the bridge crane. 


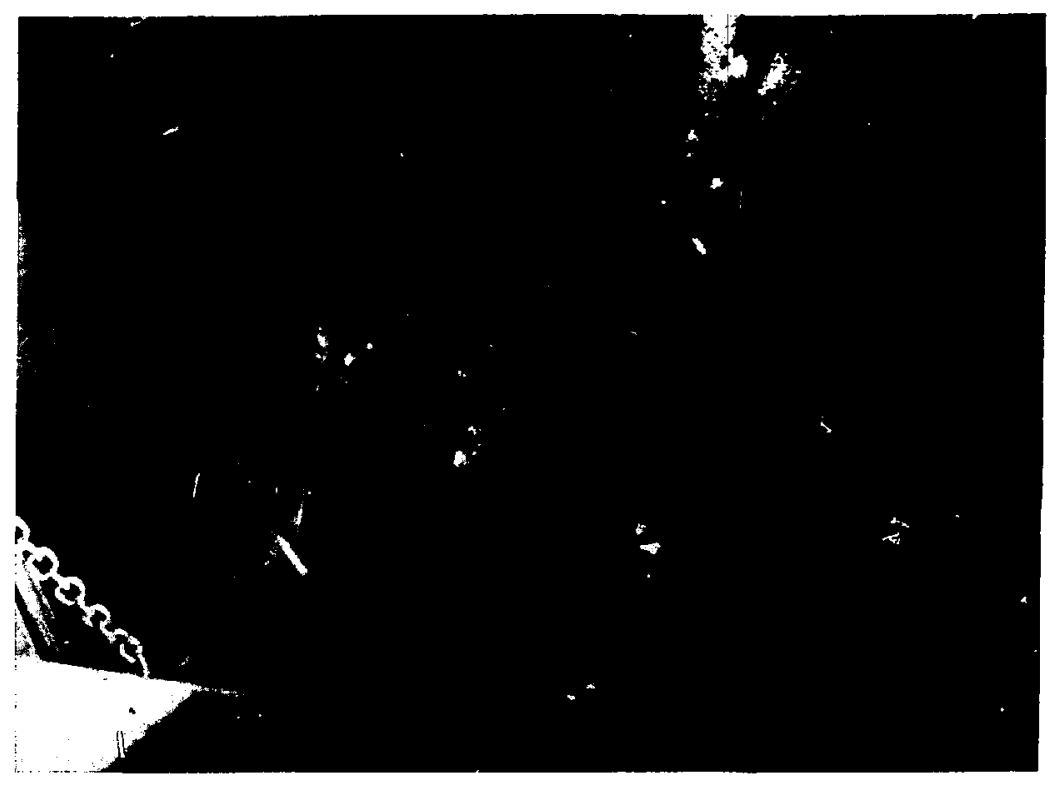

Figure 33. Four of the six central-sell modules in place on the center-vessel support sirueture. 


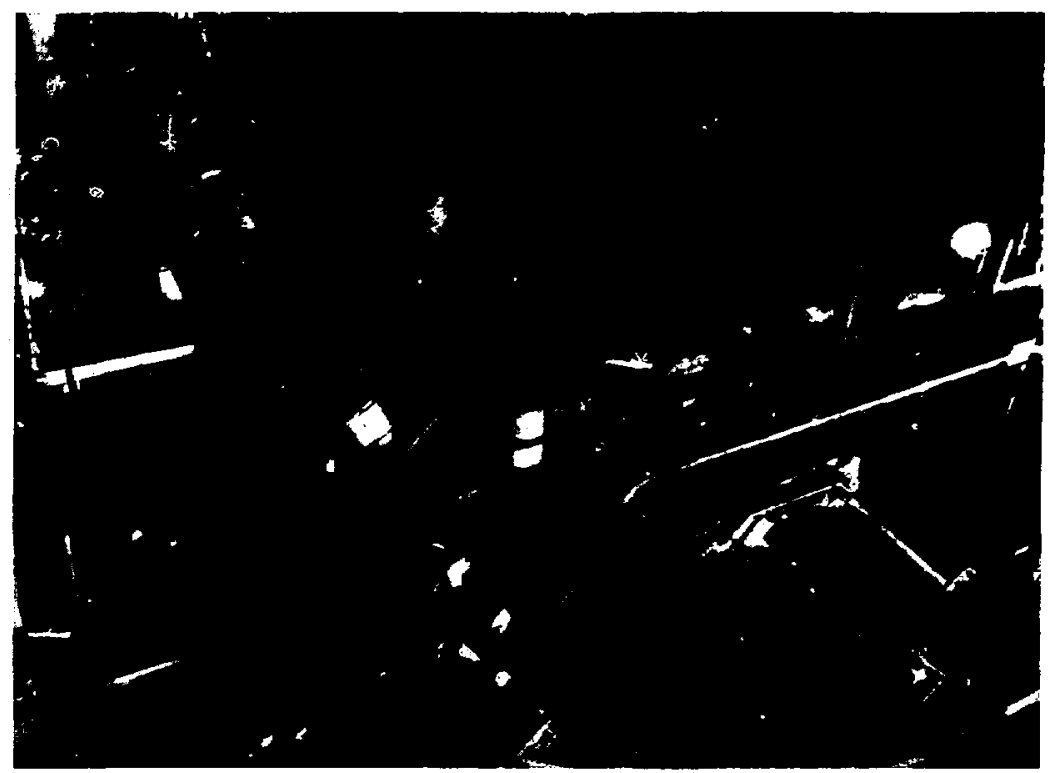

Figure 34. A view looking west from the top of the concrete-vault wall. The end dome has not been installed on the east vessel yet, giving a view of the cryopanels in the end-cell region. 


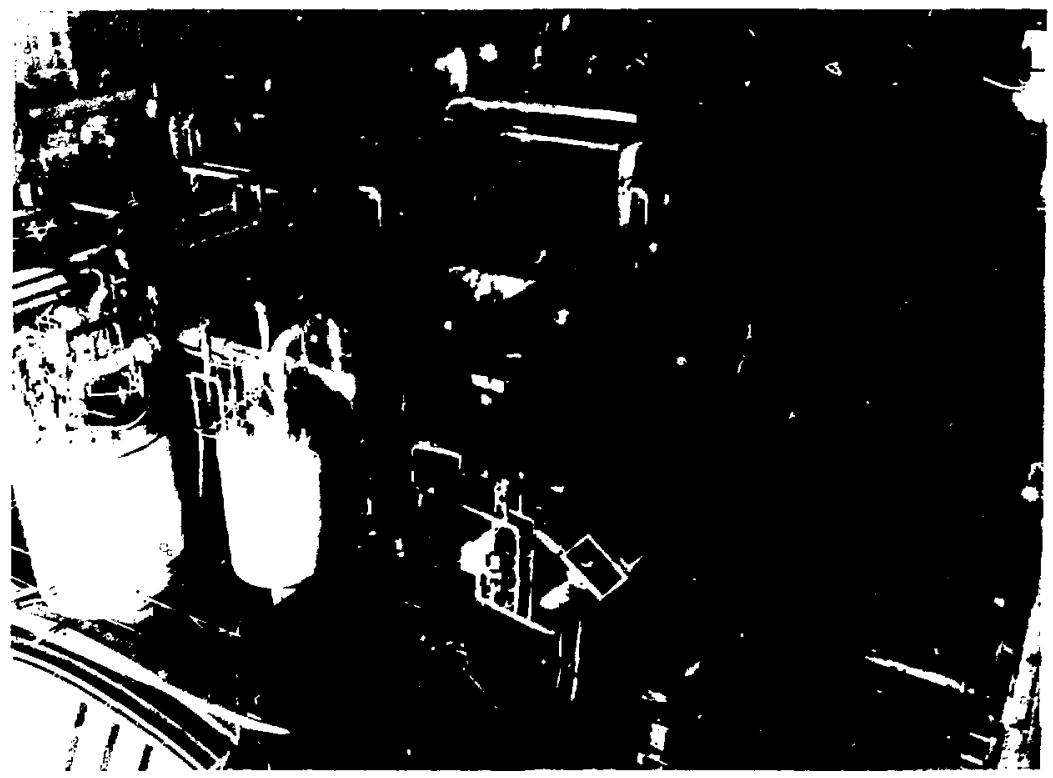

Figure 35. Another overall view of the MFTF-B vacuum vesel, but from the west end. The anxiliary equipment installed on the vacuum vessel obscures its main festures, but gives an indication of the complexity of assembling this $r$.. chine. The large lanks in the left foreground re the liquid-helium-storage Dewars that feed the cryopanels and magnets. Most of the pipes visible are cryogenic-fluid-transfer or vacuum-pamping lines. 


\section{References}

1. J. W. Gerich, "Design and Construction of the Vacuum Vessel for the Tandem Mirroz Fusion Test Facility," in Proc. of the 9th Infernational Vacuum Conference, Madrid, Spain, September 25-October 1, 1983.

2. P. J. Fleming and W. C. Chronis, "Design Features of the Vacuum Vessel and Cryopumping System for MFTF-B Axicell, Pittsburgh-Des Moines Corporation, Pittsburgh, PA," in Proc. of the 10h IEEE Symposium on Engineering Problems of Fusion Research, Philadelphic, PA, December 5-9, 1983.

3. B. J. Schumacher and W. R. Call, Cryopumping Hydrogen Isolope Mixtures in MFTF-B with and without Argon Adsorbent, Lawrence Livermore National Laboratory, Livermore, CA, UCRL-92055 (1985).

4. S. J. Sackett, Users Manual for SAP4, Lawrence Livermore National Laboratory, Livermore, CA, UCID-18226 (May 1979).

5. H. J. Weaver, D. B. McCallen, and M. W. Eli, Dynamic Testing of the MFTF Containment Vessel Structural System, Lawrence Livermore National Laboratory, Livermore, CA, UCRL-53307 (1902).

6. V. N. Karpenko and D. S. Ng "Application of Structural-Mechanics Methods to the Design of Large Tandem-Mirror Fusion Devices (MFTF-B)," in Proc. of the Bth International Conference on Structural Mechanics in Reactor Technology, Brussels, Belgium, August 19-23, 1985.

7. D. S. Ng. "Static and Dynamic Analyses on the MFIF-B Vacuum Vessel," in Proc. of the 10th IEEE Symposium on Engineering Problems of Fusion Research, Philadelphia, PA, December 5-9, 1983.

8 O. R. Maslenikov, L. W. Tiong, and J. J. Johnson, Seismic Analyses for the Mirror Fusion Test Facility: Soil-Structure-Interaction Analyses of the Vessel, Structural Mecharics Associates, San Ramon, $\mathrm{CA}$ (1984).

9. D. S. $\mathrm{Ng}$. The Final Report of Static and Dynamic Analyses on the MFTF-B Axicell Vacuum Vessel System, Lawrence Livermore National Laboratory, Livermore, CA, UCRL-53723 (1985). 